
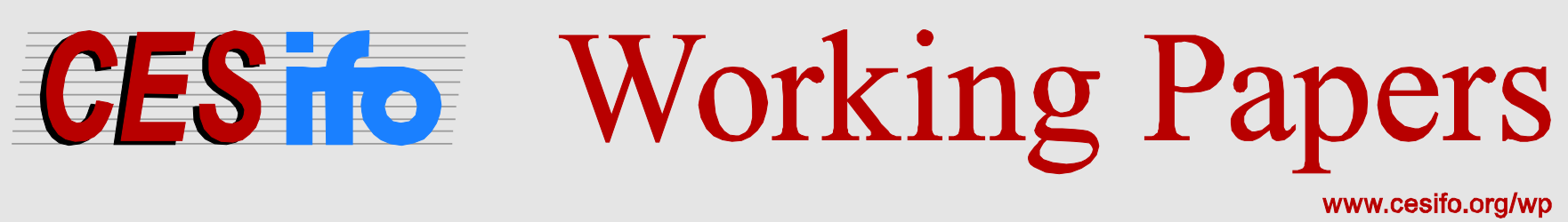

\title{
Let the Market Decide: An Experimental Study of Competition and Fairness
}

\author{
Björn Bartling \\ Manuel Grieder \\ Christian Zehnder
}

CESIFO WORKING PAPER NO. 4831

CATEGORY 13: BEHAVIOURAL ECONOMICS

JUNE 2014

An electronic version of the paper may be downloaded

- from the SSRN website:

- from the RePEc website:

- from the CESifo website:

WWW.SSRN.com

www.RePEc.org

www.CESifo-group.org/wp

\section{CESifo}




\title{
Let the Market Decide: An Experimental Study of Competition and Fairness
}

\begin{abstract}
Is competition perceived as a fair procedure? We report data from laboratory experiments where a powerful buyer can trade with one of several sellers. Sellers who feel shortchanged can engage in counterproductive behavior to punish the buyer. We find that the same unfavorable terms of trade trigger significantly less punishment if the buyer uses a competitive auction to determine the terms of trade than if she uses her authority to dictate the same terms directly. Our results inform the debate on the fairness of market outcomes by showing that the use of a competitive procedure can, by itself, affect how people judge unequal distributive outcomes.
\end{abstract}

JEL-Code: C910, D030, D630.

Keywords: competition, authority, markets, fairness, responsibility, procedures.

\author{
Björn Bartling \\ Department of Economics \\ University of Zurich \\ Blümlisalpstrasse 10 \\ Switzerland - 8006 Zurich \\ bjoern.bartling@econ.uzh.ch
}

\author{
Manuel Grieder \\ Faculty of Business and Economics \\ (HEC Lausanne) / University of Lausanne \\ Quartier UNIL-Dorigny, Internef \\ Switzerland - 1015 Lausanne \\ manuel.grieder@unil.ch
}

\author{
Christian Zehnder \\ Faculty of Business and Economics \\ (HEC Lausanne) / University of Lausanne \\ Quartier UNIL-Dorigny, Internef \\ Switzerland - 1015 Lausanne \\ christian.zehnder@unil.ch
}

May 23, 2014

We gratefully acknowledge support from the Swiss National Science Foundation. We thank Martin Dufwenberg, Florian Ederer, Armin Falk, Ray Fisman, Bob Gibbons, Holger Herz, Raj Iyer, Andrea Pratt, and Roberto Weber, as well as seminar participants at Auckland, Columbia, Göttingen, MIT, Lausanne, and Zurich, and conference participants at the IMEBE 2013, the ESA World Meetings 2013, the Nordic Conference on Behavioral and Experimental Economics 2013, the Workshop on Incentives, Motivation and Cooperation, Stavanger 2013, the CESifo Area Conference on Behavioural Economics 2013, and the NBER Organizational Economics Meetings 2013 for helpful comments. We are grateful to Michael Kosfeld for allowing us to use the FLEX lab in Frankfurt, and we especially thank Pascal Knodt for excellent research assistance. 


\section{Introduction}

Competition is a cornerstone of economics. It is associated with the efficient allocation of resources and with individual liberties such as free market entry and the exercise of choice. But is it also perceived as a fair procedure? In this paper, we analyze experimentally the impact of the use of a competitive procedure - relative to the use of authority - on counterproductive behavior in response to unequal distributive outcomes.

The importance of people's judgments of distributive market outcomes is vividly highlighted by the public debate triggered by Piketty (2014), who documents rising wealth inequality in recent decades and admonishes that such inequalities can potentially trigger social discontent. Indeed, it is well documented that many people dislike inequality and are willing to sacrifice monetary gains to take retaliatory actions against others whom they blame for unfair outcomes (e.g., Fehr \& Fischbacher, 2003). The prevalence of such punishments is a mixed blessing. In some situations the punishment of perceived unfairness can, in the long run, help to support social norms or cooperation (e.g., Gächter et al., 2008). In other situations conflict and counterproductive behavior triggered by perceived unfairness can create substantial deadweight losses (e.g., Nikiforakis, 2008). Understanding how procedures affect perceived fairness and reactions to inequality is thus important also from an efficiency point of view.

The inherent fairness of market procedures is widely discussed in public debate as well. A recent prominent example is Sandel (2012), who questions that the use of markets to allocate certain goods and services is generally just - relative to other "non-market" allocation rules (for a reply see Besley, 2013). People's fairness judgments of market procedures are, to date, rarely addressed in the economics literature. An early exception is Kahneman et al. (1986), who provide survey evidence that many people regard market mechanisms as unfair-at least in certain situations. In contrast, Hart \& Moore (2008) hypothesize, more recently, that competition is perceived as fair because it "provides a relatively objective measure of what B[uyer] and S[eller] bring to the relationship" (p. 12).

The idea that the same outcome is judged differently depending on the procedure that leads to it is deeply entrenched in psychology (e.g., Thibaut \& Walker, 1975). The research on procedural fairness in economics largely focuses on the role of biased vs. unbiased random procedures to capture the idea of equal opportunity, "level playing field," or ex-ante fairness (e.g., Bolton et al., 2005; Cappelen et al., 2013). Given the central role that competition plays in markets, business life, and many realms of society at large, it is of high interest to better understand if and how the procedure of competition affects, by itself, people's reactions to unequal distributive outcomes. 
The procedure of competition comes in many forms. The aim of this paper is not to provide a comprehensive definition of the precise nature and boundaries of competitive procedures or markets. Rather, our research strategy is to use very simple controlled laboratory experiments to elicit the behavioral reactions to the outcomes of one specific competitive procedure - an auction - and to compare it to a clearly specified procedural alternative - the use of authority - that can result in the same distributional outcomes.

Our experimental design reflects a stylized trading situation where a powerful buyer can trade with one of two possible sellers. The terms of trade - that is, the markup that the buyer pays on top of the seller's cost - are reflected in the number of points that the buyer transfers to one of the sellers. The buyer can choose between two different procedures. She can either use authority to set the transfer directly, in which case one seller receives the transfer and the other gets nothing, or she can let the transfer be determined in a competitive clock auction. In the clock auction, the transfer starts at zero and increases by one point each second until one of the sellers accepts. The seller who accepts first receives the transfer, the other gets nothing. After the procedure is chosen and the transfer is determined, the sellers can engage in counterproductive behavior. This is implemented in form of a costly punishment option that allows retaliating against the buyer and/or the other sellers. ${ }^{1}$ The observed punishment serves as a measure of perceived fairness violations and responsibility attribution for the distributive outcome resulting under the chosen procedure.

For given distributive outcomes, we find that the procedure of competition triggers less punishment for the buyer than the use of authority. Moreover, we find that using competition leads to a partial shift of the blame. While the buyer is punished less under competition, the sellers punish each other more. Importantly, the increase in mutual punishment of the sellers is smaller than the reduction in the punishment of the buyer. The use of competition thus decreases the total amount of counterproductive behavior, i.e., it decreases the inefficiencies caused by conflicting views about the fairness of the resulting distributive outcome.

Consider procurement auctions as one example for the implications of our findings. The existing literature argues that asymmetric information with respect to sellers' production costs is the key reason for the use of such auctions (see, e.g., Klemperer, 1999). Our paper shows that the reasons for the use of competitive procurement auctions go beyond eliciting sellers' costs. Relative to a situation where a powerful buyer simply dictates a low price that

\footnotetext{
${ }^{1}$ The counterproductive actions in our experiment correspond to what Hart \& Moore (2008) call performance shading. Shading can occur in various forms. For example, imagine that a buyer faces multiple sellers. One obvious way in which the selected seller can hurt the buyer is by lowering the quality of the product or service delivered to the buyer (lowering the quality may be costly if there is a risk of detection or if the seller himself prefers delivering a high quality product). Another common and potentially powerful form of shading is malicious gossip. This kind of punishment can be used by both selected and rejected parties and may be targeted at both trading partners and competitors.
} 
leaves, say, just a small markup on top of costs, sellers judge the same low prices as more justified when they are competitively elicited, and thus engage less in quality shading.

To study the robustness of our results, we implemented three additional conditions, each of which varies one important feature of our baseline condition. In the intense competition treatment we intensify the competitive pressure in the auction by increasing the number of potential sellers. This drives down transfers under competition and might therefore render the use of competition less acceptable. In the symmetric access treatment it is randomly determined which buyer receives the transfer if the buyer uses authority, while the transfer goes to a predetermined buyer in the baseline condition. We thus eliminate the feature of our baseline condition that only competition grants equal ex-ante opportunities to all sellers to receive a transfer. This removes a potential justification for the choice of the competitive procedure and might thus decrease its perceived fairness. In the involvement treatment the buyer has to determine the sequence of offers that are shown in the clock auction, instead of the exogenously given sequence with increments of one point. This implies that the buyer has a direct impact on the outcome of the competitive process, which might increase the attributed blame. We find that the results obtained in the baseline condition persist in all three treatment variations. This suggests that employing a competitive procedure is a robust method to reduce blame assigned to the buyer and overall counterproductive behavior in response to unequal distributive outcomes.

In the next section we discuss the relationship of our paper to the existing literature. Section 3 describes the study design in detail, and Section 4 presents the results. We discuss the implications of our results in Section 5 .

\section{Related Literature}

Our design builds on previous research on dictator and ultimatum games (for an overview see Camerer, 2003). A well established finding in this literature is that many people are willing to give up material payoffs to punish others for the choice of unequal payoff allocations. There is a consensus that these punishments represent retaliatory actions in response to perceived unfairness.

In our experimental setup, the buyer can choose between two different proceduresauthority or competition - to determine the allocation of payoffs among herself and the sellers. After having observed the transfer, one of the two sellers decides whether to assign costly punishment points to the buyer and/or the other seller. This allows studying not only how sellers react to given allocations but also whether they react differently to the same outcome depending on the procedure that was chosen to determine the payoffs. 
Previous work has investigated the effect of competition in ultimatum games (Güth et al., 1998; Marchand, 2001; Grosskopf, 2003; Fischbacher et al., 2009). These studies show that competition among receivers drastically increases their willingness to accept low offers. ${ }^{2}$ While many receivers reject allocations that offer them less than 30 percent of the pie in the standard ultimatum game, competition induces them to accept much smaller transfers. However, these findings do not necessarily imply that competition alters the receivers' fairness perceptions. Fehr \& Schmidt (1999) show that in an outcome-based fairness model, the same fairness preferences that motivate receivers to reject low offers in the standard ultimatum game can also induce them to accept these offers under competition. ${ }^{3}$

Our experiment differs in two important ways from ultimatum games with receiver competition. First, in ultimatum games the acceptance decision and the punishment decision are perfectly linked. This is not the case in our setup. Sellers who have accepted a transfer under competition can still punish the buyer if they perceive the realized allocation as unfair. In our experiment purely outcome-based fairness preferences can therefore not explain why sellers punish less when the same unequal payoff allocation has been determined by competition rather than authority. Second, in the studies on receiver competition in ultimatum games it is the experimenter who decides whether the decision environment is competitive or not. In our experiment, in contrast, it is the buyer who chooses the procedure under which the transfer is determined. This feature allows us to study whether sellers punish the buyer for the choice of competition or authority.

Our paper is also related to experimental studies by Fehr et al. (2009, 2011), who confirm Hart \& Moore's (2008) hypothesis that a competitively negotiated ex-ante contract provides a reference point for ex-post trade (see also Bartling \& Schmidt, 2014). Fehr et al. take a competitive environment as given and focus on the impact of the buyer's choice between a rigid and a flexible contract on sellers' ex-post counterproductive behavior. In contrast, we focus on the buyer's choice of procedure - authority or competition - on counterproductive behavior by sellers, not on the choice of a contract type.

Finally, our paper contributes to the literature on the diffusion of responsibility. Psychological studies show that responsibility is diffused in groups, known as the "bystander effect" (Darley \& Latane, 1968), and recent studies in economics show that responsibility diffusion leads to more selfish behavior in economic contexts (e.g., Dana et al., 2007; Hamman et al., 2010; Falk \& Szech, 2013). The punishment pattern in our paper is consistent with the idea that responsibility diffusion creates "moral wiggle room" and reduces blame, because the

\footnotetext{
${ }^{2}$ Roth et al. (1991) conduct an ultimatum game with proposer competition.

${ }^{3}$ The reason is that the presence of competing receivers implies that a single receiver cannot ensure punishment of the proposer by rejecting a low offer. There is always the possibility that another receiver accepts, in which case the rejecting receiver lowers his expected payoff without affecting the proposer's payoff.
} 
buyer is the only person who makes a decision if she uses authority, while also one of the sellers has to make an active acceptance decision if the buyer chooses competition. Further, Bartling \& Fischbacher (2012) show that delegation of a potentially unpopular decision to another person or a random device avoids punishment for unfair outcomes (see also Coffman, 2011). Our paper reveals that it is possible for economic actors to deflect blame by delegating choice to a competitive procedure and "let the market decide."

\section{Experimental Design}

Consider the following situation: a powerful buyer can trade with one of several sellers, either by setting the terms of trade directly or by delegating the determination of the terms of trade to a mechanism that puts the sellers into competition with each other. Sellers who feel shortchanged can engage in costly counterproductive behavior, such as sabotage or performance shading. Our experimental strategy is to capture this trading situation in the simplest possible design.

\subsection{Baseline}

We implement a three-player game with one buyer and two sellers: the buyer has an endowment of 90 points and the two sellers have an endowment of 10 points each. The buyer must implement a transaction with one of the sellers. A transaction is implemented simply by transferring an integer amount $t \in[0,40]$ to one of the two sellers. The transfer can be interpreted as the markup that the buyer pays to the seller on top of the seller's cost. The default is thus that the buyer receives the entire surplus from trade, represented by her large endowment, but she can set a positive transfer to share parts of the surplus with one seller. The transfer can either be set directly by the buyer, using authority, or it can be determined via competition. One randomly chosen seller can finally allocate costly punishment points

to the buyer and/or the respective other seller. In the following we provide a step-by-step account of the game and describe each player's decisions in detail.

Step 1: Buyer's choice of the procedure

The buyer (player A) first decides whether to use authority or competition to determine the transfer $t$ that goes to one of the two sellers (players B and $\mathrm{C}$ ).

If A chooses authority she can directly determine how many points $t$ she wants to transfer to the seller, as in a standard dictator game. Importantly, under authority the transfer always goes to $\mathrm{B}$, it never goes to $\mathrm{C}$. 
If A chooses competition, the transfer is determined by an increasing clock auction. The transfer starts at 0 points and automatically increases by one point each second. As under authority, the maximum transfer is 40 points. Should the clock auction arrive at a transfer of 40 points (after 40 seconds), it does not increase further. The auction however stops as soon as one of the two sellers accepts the current transfer. The transfer can thus go to either B or C, depending on who accepts first. ${ }^{4}$

Step 2: Sellers' punishment decisions

After A has chosen a procedure and the transfer (and in case of the auction also the winner) is determined, either $\mathrm{B}$ or $\mathrm{C}$ is randomly selected. The selected seller receives additional 5 points, which he can keep or use, in part or all, to punish the other players. To destroy one point of another player, the selected seller must give up 0.1 points of his own. He can deduct a maximum of 50 points in total from the other two players. Punishments can reduce a player's profit down to 0 , but we do not allow for negative profits.

To maximize the number of observations, we elicited punishment decisions using a variant of the strategy method. First both sellers decide privately how many points, if any, to deduct from the other players. Only thereafter it is randomly determined whether B's or C's decisions are implemented. ${ }^{5}$

\section{Step 3: Payoffs}

In the following we summarize the players' payoffs. Table 1 displays the intermediary payoffs $\tilde{\pi}$ resulting from the game before punishment. Table 2 shows the final payoffs $\pi$ that result after one of the sellers is selected to be able to punish and the punishment points $p$ have been assigned. The game was played repeatedly for 12 periods with fixed role assignments and random matching. In the end one period was randomly selected for payment.

Table 1: Intermediate Payoffs before Punishment

\begin{tabular}{lccc}
\hline & Authority & \multicolumn{2}{c}{ Competition } \\
& & $B$ wins & $C$ wins \\
\hline$\tilde{\pi}_{A}$ & $90-t$ & $90-t$ & $90-t$ \\
$\tilde{\pi}_{B}$ & $10+t$ & $10+t$ & 10 \\
$\tilde{\pi}_{C}$ & 10 & 10 & $10+t$ \\
\hline Notes: A has an initial endowment of 90 points and B and C have an initial \\
endowment of 10 points each. The intermediate payoffs for A, B, and C are shown \\
as a function of the transfer $t$ that goes from the buyer (A) to the seller (B or C).
\end{tabular}

\footnotetext{
${ }^{4}$ The feature of our design that $\mathrm{C}$ is excluded from receiving the transfer under authority, but has potential access to the transfer under competition, reflects the property of free entry to competitive markets. See our discussion of the symmetric access treatment in Section 3.2.2.

${ }^{5}$ Alternatively, we could have given punishment rights to both sellers simultaneously. However, this would have created the potential for strategic counter-punishment among the sellers and thus confounded the use of the punishment decisions as a measure of fairness violations and the attribution of blame. Moreover, our design avoids a public goods problem with respect to the punishment of the buyer.
} 
Table 2: Final Payoffs

\begin{tabular}{lcc}
\hline & B can punish & $C$ can punish \\
\hline$\pi_{A}$ & $\tilde{\pi}_{A}-p^{A}$ & $\tilde{\pi}_{A}-p^{A}$ \\
$\pi_{B}$ & $\tilde{\pi}_{B}+5-0.1 \cdot\left(p^{A}+p^{C}\right)$ & $\tilde{\pi}_{B}-p^{B}$ \\
$\pi_{C}$ & $\tilde{\pi}_{C}-p^{C}$ & $\tilde{\pi}_{C}+5-0.1 \cdot\left(p^{A}+p^{B}\right)$ \\
\hline
\end{tabular}

Notes: The seller who can punish receives 5 points extra. Each punishment point $p$ assigned to another player reduces the punisher's payoff by 0.1 points. Superscripts denote the target of punishment.

\subsection{Treatment Conditions}

\subsubsection{Intense Competition Treatment}

An important characteristic of a competitive procedure is the intensity of competition. The more intense the competition between the sellers, the more likely a low transfer will result. More intense competition might thus trigger more counterproductive behavior by sellers. Hence, in the intense competition treatment we implemented a four-player version of the baseline by adding a player $\mathrm{D}$ who is a "clone" of $\mathrm{C}$ in every respect. ${ }^{6}$ If A chooses competition, there are now three players - B, C, and D-who compete for receiving the transfer. If A chooses authority in the intense competition treatment, the rules are as in the baseline in that the transfer always goes to $\mathrm{B}$, and never to $\mathrm{C}$ or $\mathrm{D}$.

\subsubsection{Symmetric Access Treatment}

A desirable feature of competitive markets is free entry, which distinguishes a competitive market from other, less "open" procedures, such as, for example, a regulated market where entry is restricted. To capture this relative advantage of competition, both $\mathrm{B}$ and $\mathrm{C}$ have the chance to receive the transfer under competition in all our treatments, while $\mathrm{C}$ is excluded from the transaction, by design, under authority in the baseline treatment. The symmetric access treatment isolates this feature by providing equal access to the transaction even under authority. Specifically, if A chooses authority in the symmetric access treatment, she first sets the transfer and it is then randomly determined, with equal probability, whether $\mathrm{B}$ or $\mathrm{C}$ receives the transfer. If $\mathrm{A}$ chooses competition in the symmetric access treatment, the rules are exactly as in the baseline.

\footnotetext{
${ }^{6}$ Recall that we use the strategy method to elicit punishment decisions. The presence of player D means that the probability that a given seller's punishment decision is implemented is reduced from $1 / 2$ to $1 / 3$.
} 


\subsubsection{Involvement Treatment}

The automated clock auction that is used to determine the transfer under competition in the baseline treatment is a mechanical process. In particular, once A chooses competition, the transfer paid to the seller is determined entirely by the acceptance decisions of $\mathrm{B}$ and $\mathrm{C}$, without any involvement by A. This might make it easier for the buyer to "hide" behind the forces of competition and to avoid the blame associated with low outcomes. In reality, however, buyers are often actively involved in the negotiation process even under competition, for example by making offers to several sellers simultaneously. In the involvement treatment, we therefore give $\mathrm{A}$ an active part in the auction.

If A chooses competition in the involvement treatment, she first has to set a sequence of ten strictly increasing transfer offers. ${ }^{7}$ In the actual auction, A's transfer offers are then made to $\mathrm{B}$ and $\mathrm{C}$ in increasing order. Each offer is displayed to the sellers for 1.5 seconds before the next higher offer is shown. ${ }^{8}$ As in the baseline, the seller (B or $\mathrm{C}$ ) who first accepts an offer gets the transfer. If none of A's ten offers is accepted (after 15 seconds), the highest transfer offer is automatically increased by one point each second up to the maximum transfer of 40, exactly as in the baseline. ${ }^{9}$ If A chooses authority in the involvement treatment, the rules are exactly as in the baseline.

\subsection{Data Collection and Procedural Details}

The experiments were conducted at the FLEX lab at Goethe-University in Frankfurt, Germany, in June, July, and November 2012. Participants were recruited from the regular subject pool, covering all fields of study, using ORSEE (Greiner, 2003). The experiments were computerized using z-Tree (Fischbacher, 2007).

We ran seven sessions for each of the four treatments, with 619 subjects in total (310 women and 309 men). We aimed at 24 subjects per sessions but some sessions were smaller due to no-shows. All but one session had at least 20 subjects; a single session of the involvement treatment had 15 subjects only. Treatments were randomly assigned to sessions and participants were randomly assigned to roles. Interactions were anonymous.

Subjects received detailed written instructions at the beginning of a session and had to correctly answer several control questions before the experiment was started. A summary

\footnotetext{
${ }^{7}$ If the sequence reaches the maximum transfer of 40 before the tenth offer, it cannot increase further.

${ }^{8}$ The buyer's sequence of transfer offers was shown to the two competing sellers before the start of the auction. We nevertheless slowed down the clock auction because it is much more demanding for the sellers to process the buyer's sequence of increasing offers than to follow the standard clock auction with constant increments of 1 point.

${ }^{9}$ In case A's highest proposal is already 40, the clock auction does not increase the transfer anymore.
} 
of the instructions was read aloud to ensure common knowledge of all rules. The experiment was framed neutrally. The roles in the experiment were not labeled as "buyers" and "sellers," instead we simply referred to roles A, B, C, or D. A translation of the original German instructions is in Appendix C. Subjects finally answered a questionnaire containing demographics and some personality measures (see our discussion in Section 4.4). Sessions lasted for 75 to 90 minutes including the reading of the instructions and the final payment. Subjects received a show-up fee of 10 EUR and experimental points were exchanged at a rate of five points per Euro. The average total earnings were 16.44 EUR; 24.44 EUR for subjects in the role of $\mathrm{A}$, and 12.79 EUR for subjects in the role of $\mathrm{B}, \mathrm{C}$, or D.

\section{Results}

\subsection{Main Results}

Panel A of Figure 1 shows that competition reduces the punishment of the buyer in the baseline treatment. The solid lines in the graph show the average number of points that are deducted from the buyer as a function of the transfer level (i.e., the markup paid to the seller). ${ }^{10}$ The important observation is that the procedure matters: for given transfer levels, the buyer is punished less when the transfer is determined competitively than when the buyer relies on authority to set the transfer directly. The figure also illustrates that transfer levels matter: the punishment of the buyer decreases with increasing transfers. We summarize the impact of the procedure on punishment for the buyer in our first result.

RESULT 1: For a given transfer level, sellers punish the buyer less if the transfer has been determined competitively rather than through authority.

Table 3 reports regression results and confirms the statistical significance of this effect. The dependent variable in regressions (1) and (2) is the punishment for the buyer. Authority is the omitted category. "Competition" is a dummy variable that takes on value 1 if an observation comes from the competitive procedure, and value 0 otherwise. Column 1 reports an OLS regression and column 2 a Tobit regression that is censored at the maximum punishment level of 50 . The coefficient of the competition dummy is negative and highly significant in both regressions $(p<.01)$.

\footnotetext{
${ }^{10}$ Recall that we use the strategy method to elicit punishment. The numbers shown are the averages of all punishment decisions, irrespective of whether a seller was selected to be able to punish or not.
} 
Figure 1: Punishment patterns in the treatment variations
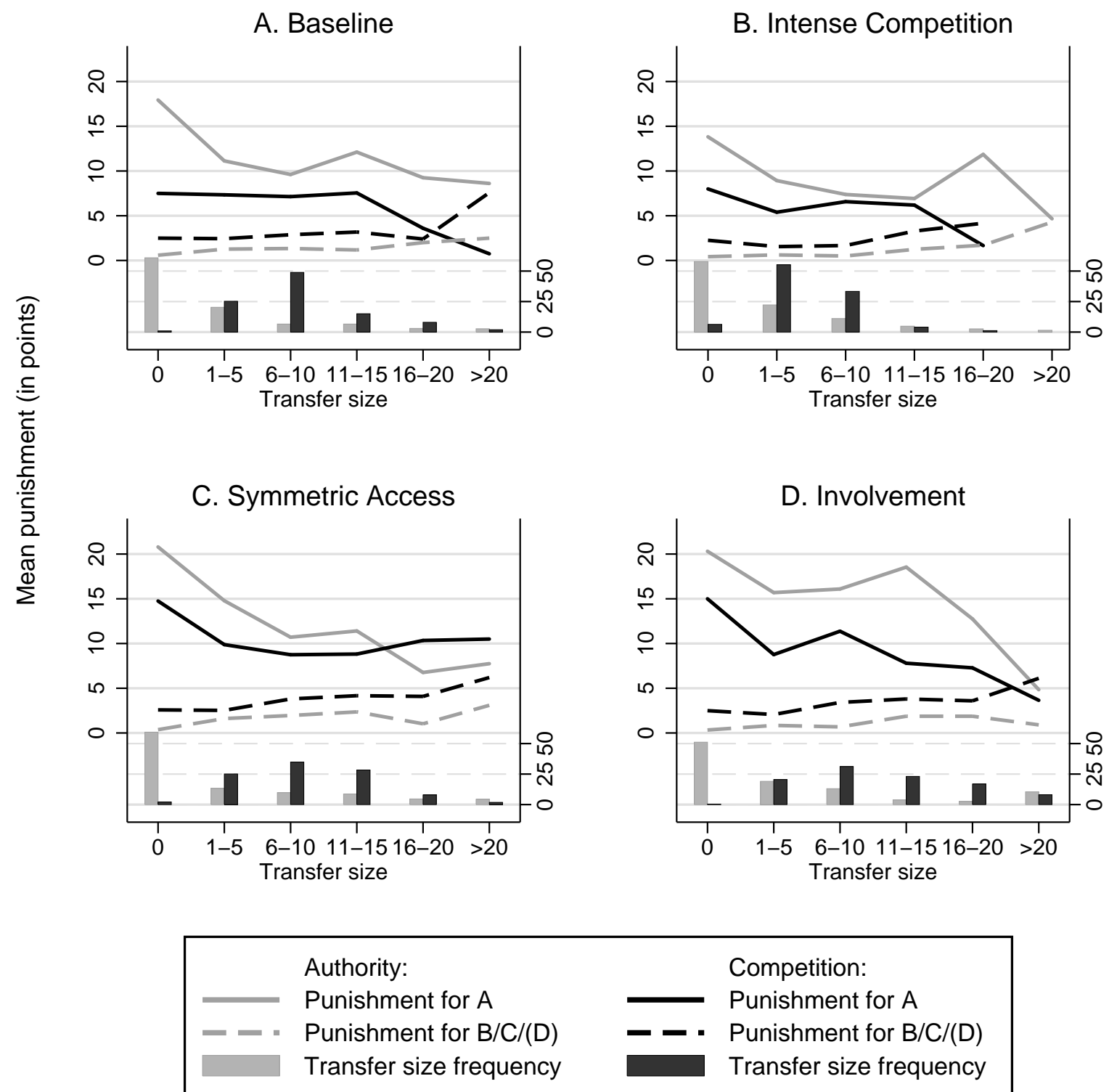

Notes: For the intense competition treatment (panel B) the dashed lines represent the sum of punishment assigned to the other two sellers. 


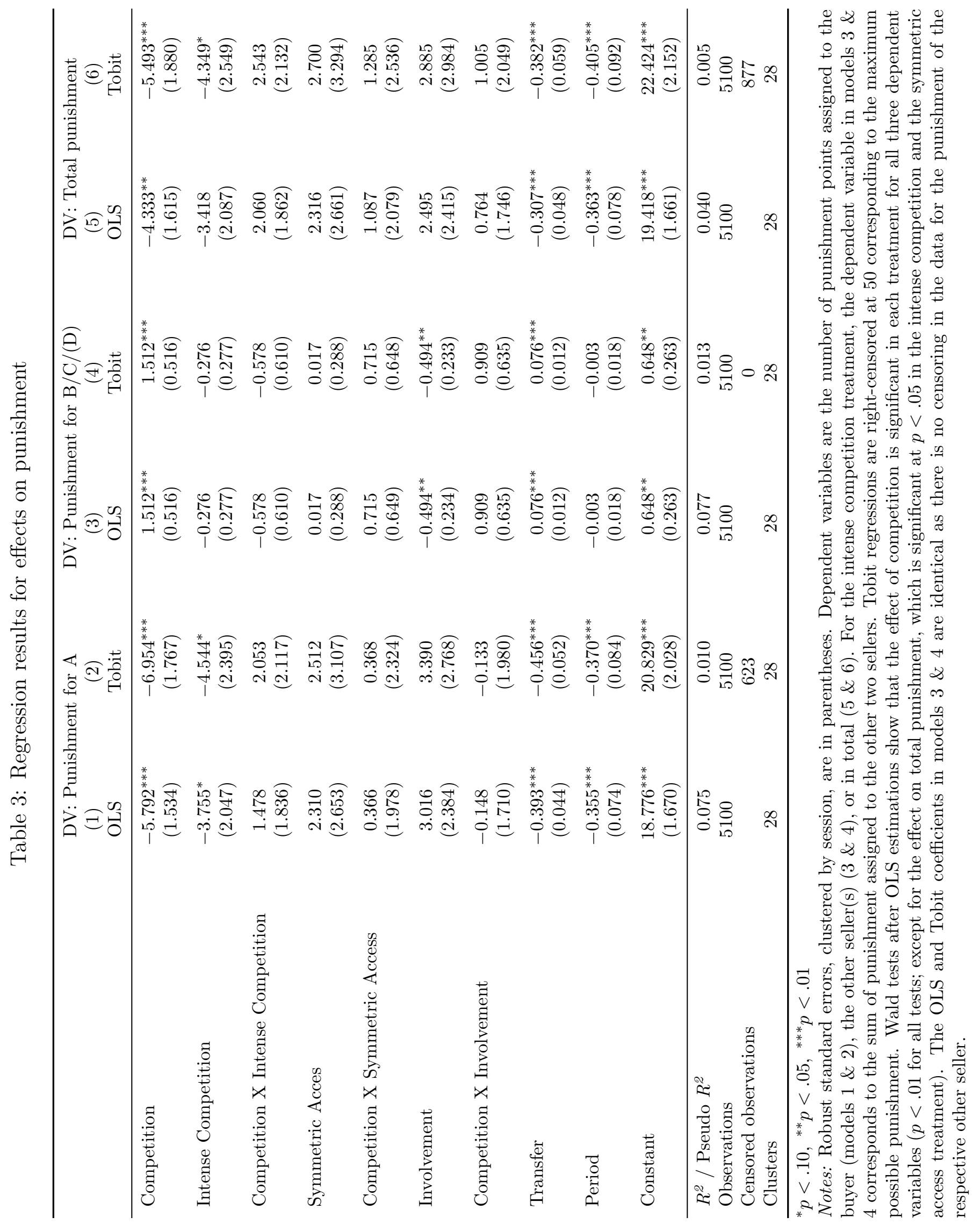


The regressions also control for the transfer level, the period of observation, and they include treatment dummies and their interaction with the competition dummy. The negative and significant coefficient of "Transfer" confirms that punishment is lower for higher transfers. The negative and significant coefficient of "Period" reveals that punishment generally declines over the course of the 12 periods of the experiment. We discuss the treatment dummies in Section 4.2. ${ }^{11}$

The two dashed lines in Panel A of Figure 1 show the average punishment that the sellers inflict on each other. The figure shows that the sellers punish each other more when the buyer chooses competition than when she chooses authority. Also, transfer levels again matter; the mutual punishment increases with the transfer. This is summarized in our second result.

RESULT 2: For a given transfer level, sellers punish each other more if the transfer has been determined competitively rather than through authority.

Regressions (3) and (4) in Table 3 confirm the statistical significance of this effect. The dependent variable in these regressions is the punishment for the respective other seller; otherwise regressions (3) and (4) are equivalent to regressions (1) and (2). The coefficient of the competition dummy is positive and highly significant $(p<.01)$.

Figure 2 shows average punishment under the competitive procedure separately for competition winners and losers. The figure reveals that in the baseline, but also in the other treatments, the increase in the sellers' mutual punishment under competition is driven by the sellers who lost the auction. ${ }^{12}$ This shows that the losers in competition blame the winners for having accepted a transfer offer first. The figure also reveals that auction winners and losers punish the buyer very similarly. ${ }^{13}$

Given the opposite effects of competition on the punishment targeted at the buyer and the respective other seller, the question arises whether total punishment increases or decreases. The comparison of the effect sizes displayed in Panel A of Figure 1 clearly reveals that, for given transfers, competition reduces total punishment, which we summarize next.

\footnotetext{
${ }^{11}$ Table A1 in Appendix A provides alternative regression specifications based on a two-part ("hurdle") model. The first part of these estimations models the choice whether to punish at all (linear probabilty model), and the second part models the level of punishment conditional on punishment being positive (Tobit estimation). The analysis reveals that the use of a competitive procedure affects both the frequency and the conditional amount of punishment.

${ }^{12}$ Losers punish the respective other seller significantly more than winners $(p<.01$ in all treatments; p-values from OLS regression clustered by session).

${ }^{13}$ There is no significant difference in punishment for A between competition winners and losers $(p>.10$ in all treatments; p-values from OLS regression clustered by session). In Section 4.3 we also discuss whether and how punishment patterns for A differ across seller types (B vs. C).
} 
Figure 2: Punishment under competition, differentiated by winners and losers

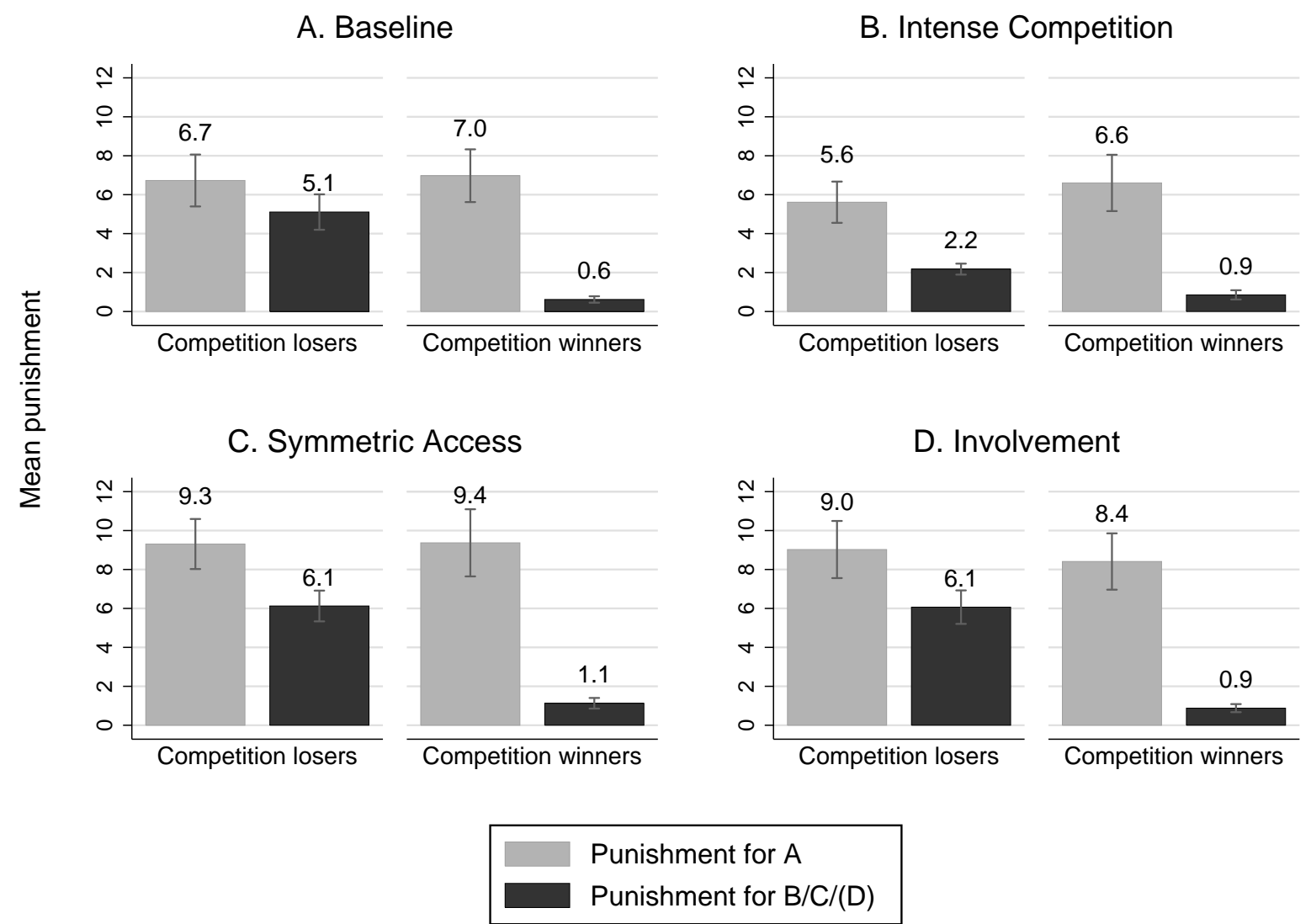

Notes: Error bars represent plus/minus one standard error of the mean, clustered by individual. For the intense competition treatment (panel B) the dark bars represent the sum of punishment assigned to the other two sellers.

RESULT 3: For a given transfer level, overall punishment - the sum of punishment targeted at the buyer and the respective other seller - is lower under competition than under authority.

The dependent variable in regressions (5) and (6) in Table 3 is total punishment; otherwise the regressions are again equivalent to the regressions reported so far. The coefficients of the competition dummy are negative and confirm the statistical significance of the reduction in total punishment $\left(p=.012\right.$ in OLS, $p<.01$ in Tobit) ${ }^{14}$

\footnotetext{
${ }^{14}$ Our paper is not meant to test a specific theory. However, it is instructive to discuss the extent to which different models of social preferences are in line with the observed punishment pattern. In Appendix B we derive predictions for sellers' punishment inclinations based on stylized versions of four different social preference theories. Specifically, we consider outcome-based fairness, intention-based reciprocity, responsibility attribution, and a formalization of the idea that competition is perceived as a fair procedure.
} 


\subsection{Robustness: Treatment Variations}

\subsubsection{Intense Competition}

Figure 1 shows for each treatment the distribution of the transfers under authority and competition, displayed at the bottom of the panels. The most notable difference between the treatments are the lower transfers under competition in the intense competition treatment compared to all other treatments. This shows that competition for transfers is indeed harsher when a third potential seller is present. The average competitive transfer amounts to 5.88 in the intense competition treatment, which is significantly lower than the average competitive transfers of 9.46, 9.90, and 12.02 in the baseline, symmetric access, and involvement treatments, respectively. ${ }^{15}$

Panel B of Figure 1 illustrates that the punishment patterns in the intense competition treatment are remarkably similar to the baseline. As in the baseline, there is less punishment for the buyer under competition, more punishment for sellers, and total punishment declines. This is confirmed by the regression analyses in Table 3. The interaction of the treatment variable "Intense Competition" with "Competition" is not significant in any of the regression models. The only (marginally) significant difference to the baseline condition is that buyers are punished generally less in the intense competition treatment; see the "Intense Competition" dummy in regressions (1) and (2), and also (6). This difference is, however, unrelated to the effect of the choice of the procedure on punishment. We thus conclude that increasing competition among sellers does not alter the effect of competition on punishment.

\subsubsection{Symmetric Access}

Panel $\mathrm{C}$ of Figure 1 shows that also in the symmetric access treatment the punishment pattern is very similar to the baseline condition - at least for transfers up to 15 points, which account for the vast majority of observations. For transfers of 16 points and higher punishment for the buyer is higher, but this region only accounts for a small fraction (about 9 percent) of the observations.

The regression results in Table 3 confirm that punishment in the symmetric access treatment does not significantly differ from the baseline. The treatment variable "Symmetric Access" and its interaction with "Competition" are not significant in any of the regression models. Hence, we conclude that it is not the free access feature of competition that drives the differences in punishment across procedures in the baseline.

\footnotetext{
${ }^{15}$ An OLS regression with treatment dummies, clustered by session, yields $p<.01$ for all three comparisons. The average competitive transfer in the involvement treatment, where the buyer sets the sequence of offers, is significantly higher than in the other treatments ( $p<.05$ for all comparisons). The competitive transfers in the baseline and the symmetric access treatment do not differ significantly from each other.
} 


\subsubsection{Involvement}

Panel D of Figure 1 again reveals a very similar punishment pattern in the involvement treatment, which is confirmed by the regression analyses in Table 3. The interaction of the treatment variable "Involvement" with "Competition" is not significant in any of the regression models. ${ }^{16}$ The only significant difference to the baseline condition is that the sellers punish each other generally less in the involvement treatment; see the "Involvement" dummy in regressions (3) and (4). This difference is small and represents a pure level effect. It does not affect the finding that competition triggers lower punishment than authority. We conclude that a stronger involvement of the buyer - at least in the way implemented in our treatment - does not alter the effect of competition on punishment.

\subsection{Robustness: Punishment by B Types}

In most of our treatments not all sellers are in the exact same position; the exception is the symmetric access treatment which we exclude from the analysis in this part. B types always receive the transfer when the buyer chooses authority, whereas $\mathrm{C}$ (and D) types have a chance to receive the transfer only when the buyer chooses competition. Obviously, these differences between the seller types may create different punishment motives. It is therefore of interest to investigate the extent to which the different punishment patterns observed for competition and authority are driven by decisions of a particular type of seller.

$\mathrm{C}$ and D types benefit from a positive expected transfer when the buyer chooses competition, while they never receive the transfer under authority. For B types, in contrast, competition creates an additional risk. Under authority they receive the transfer with certainty (though it might be zero), but under competition they only receive it if they accept first. Empirically, B types win the auction under competition in 48.9 percent of the cases across all three relevant treatments. ${ }^{17}$ Thus, although average transfers are higher under competition than under authority, ${ }^{18}$ expected transfers for B types are very similar across procedures. Under competition B types receive on average a transfer of 4.55 points and under authority the average transfer amounts to 4.79 points. ${ }^{19}$

\footnotetext{
${ }^{16}$ We do not detect systematic effects of buyers' offer patterns on punishment. Buyers' offer patterns can most straightforwardly be characterized by the first offer (the starting point), the last offer (the end point), and the mean offer. When regressing punishment for the buyer on these independent variables and controlling for transfer size and period, the results are the following: first offer $=.076(p=.692)$, mean offer $=-.193(p=.559)$, last offer $=.062(p=.707$; OLS regression clustered by individual $)$.

${ }^{17}$ The B types receive the transfer in 52.7 (baseline), 42.0 (intense competition), and 49.1 (involvement) percent of the cases.

${ }^{18}$ The transfer under competition, averaged across the three treatments discussed in this section, amounts to 9.56. This is significantly different from the average transfer of 4.55 under authority $(p<.001$ in an OLS-regression clustered by session).

${ }^{19}$ This difference is not significant ( $p=.736$ in an OLS-regression clustered by session).
} 
Based on this analysis one might suspect that the higher punishment for A under authority is predominantly driven by punishment from $\mathrm{C}$ types who punish $\mathrm{A}$ for not having chosen competition (which would have given them a chance to receive a positive transfer). ${ }^{20}$ Panels A, B, and C in Figure 3 show, however, that this is not the case. In all three treatments with different seller types, all seller types exhibit very similar punishment patterns with regard to player A: they punish A more harshly when she chooses authority than when she chooses competition. This shows that Result 1 is not driven by the punishment decisions of $\mathrm{C}$ (and D) types alone.

In particular, Figure 3 illustrates that B types punish A more under authority than under competition, even though both procedures yield very similar expected transfers for them. To further substantiate this finding, we re-run the regressions reported in columns (1) and (2) of Table 3 only with the punishment decisions made by B types. We find that our results remain basically unchanged. Most importantly, the effect of competition on punishment is of similar size and remains significant $(p=.068$ in OLS and $p=.029$ in Tobit, see regressions (1) and (2) in Table 4 for the full results). This indicates that our Result 1 also holds when considering B types only.

Finally, Panels D, E, and F in Figure 3 reveal that the increase in punishment of the respective other seller(s) does not depend on the type of seller either. Across all treatments both types of sellers increase the punishment targeted at the respective other seller(s) under competition.

\subsection{Individual Heterogeneity of Punishment Decisions}

In this section, we analyze individual heterogeneity in punishment decisions. Across all treatments 25.2 percent of the sellers (types B, C, or D) never deduct any points from any other player during the 12 periods of the experiment. The behavior of these sellers is in line with the predictions of the pure self-interest model.

The regressions reported in Table 5 show the extent to which unobserved individual differences explain the variation in punishment decisions. The dependent variable in all regressions is the punishment for the buyer. A comparison of column (1) with column (2) illustrates that including individual fixed effects increases the variance explained by the model strikingly. The $R^{2}$ rises from about 6 percent to 58 percent. Unobserved individual differences thus explain the largest part of the variance in punishment decisions. However, since the assignment of subjects to roles and treatments is random and interactions were anonymous and one-shot, our experimental design allows for a clean identification of the effect of the

\footnotetext{
${ }^{20}$ See also our discussion of intention-based reciprocity in Appendix B.
} 
Figure 3: Punishment targeted at the buyer and the other sellers by seller type

Punishment for $\mathrm{A}$

A. Baseline

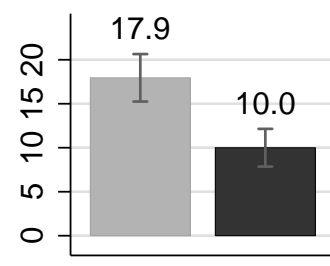

B types

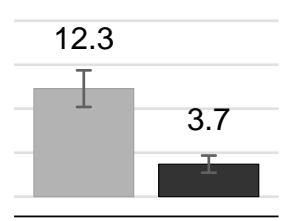

C types
Punishment for $B / C /(D)$

D. Baseline
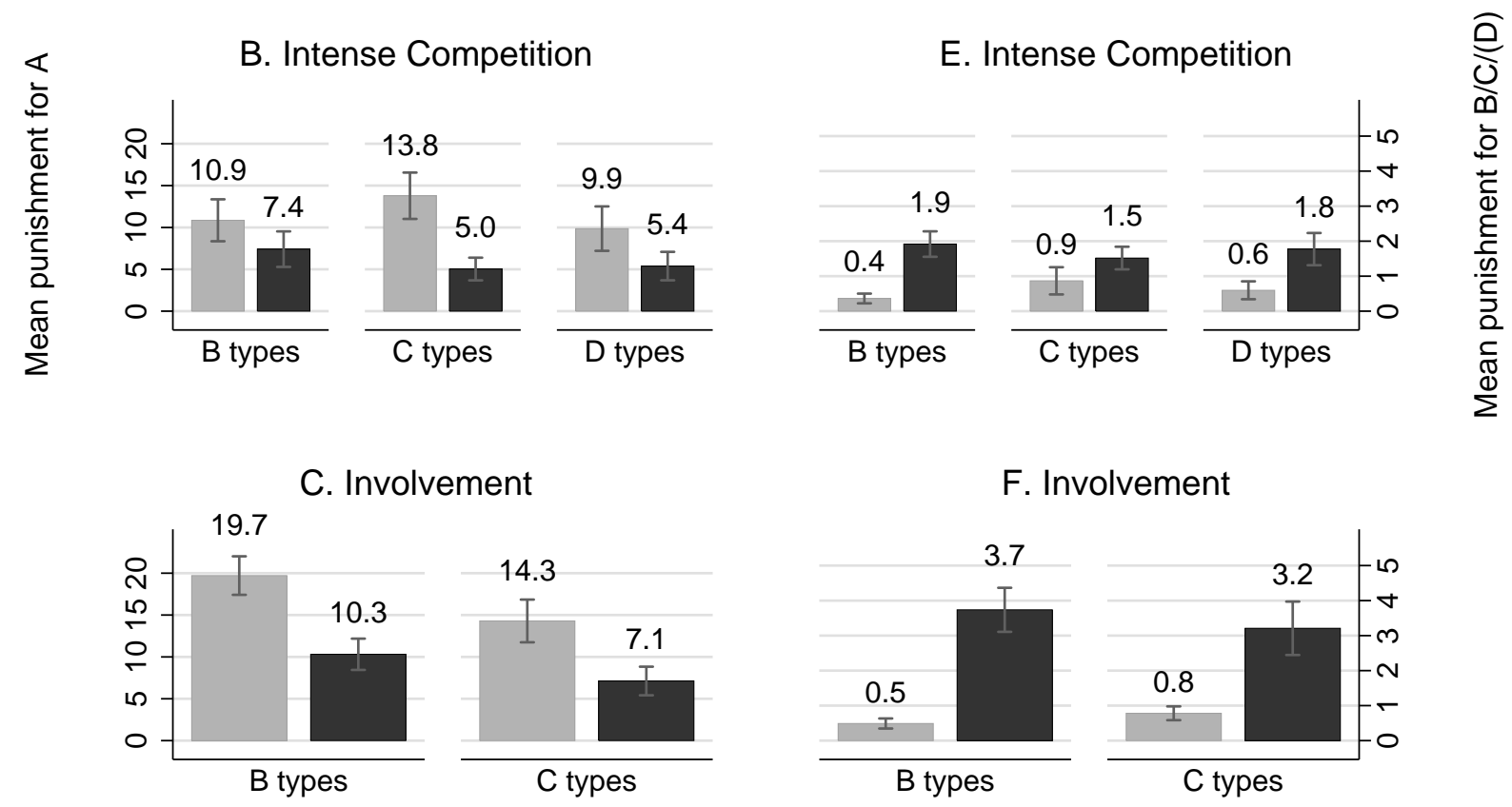

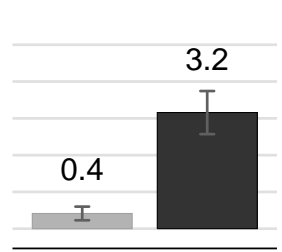

B types

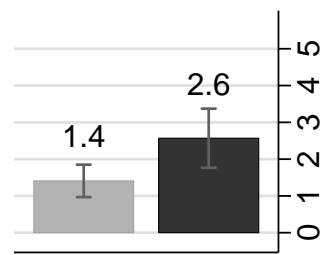

C types

F. Involvement

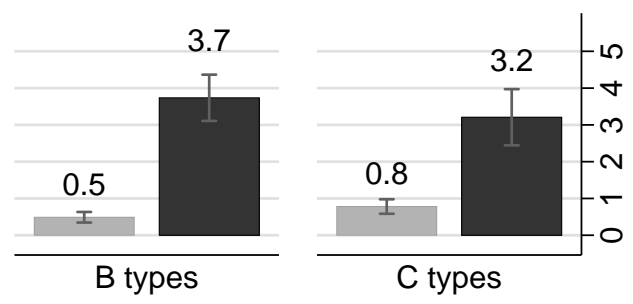

\section{Authority}

Competition

Notes: Error bars represent plus/minus one standard error of the mean, clustered by individual. In panel D (intense competition treatment) the bars represent the sum of punishment assigned to the other two sellers.

choice of procedure on punishment, despite the presence of large individual heterogeneity. Indeed, the effect size and significance level of the dummy variable "Competition" remain largely unchanged in regressions (1) and (2) in Table 5.

Regression (3) extends regression (1) by adding a "Female" dummy and its interaction with "Competition" to the explanatory variables. We find that our main result - the reduction of the punishment when the buyer chooses competition to set the transfer-is significantly less pronounced for women than for men. This can be seen by the positive 
Table 4: Robustness checks for punishment for the buyer (only B types)

\begin{tabular}{|c|c|c|}
\hline & \multicolumn{2}{|c|}{ DV: Punishment for A } \\
\hline & $\begin{array}{l}(1) \\
\text { OLS }\end{array}$ & $\begin{array}{c}(2) \\
\text { Tobit }\end{array}$ \\
\hline Competition & $\begin{array}{r}-4.414^{*} \\
(2.286)\end{array}$ & $\begin{array}{c}-6.056^{* *} \\
(2.779)\end{array}$ \\
\hline Intense Competition & $\begin{array}{c}-7.296^{* *} \\
(3.283)\end{array}$ & $\begin{array}{c}-8.864^{* *} \\
(3.989)\end{array}$ \\
\hline Competition X Intense Competition & $\begin{array}{c}2.703 \\
(2.758)\end{array}$ & $\begin{array}{c}3.875 \\
(3.325)\end{array}$ \\
\hline Involvement & $\begin{array}{c}3.402 \\
(3.495)\end{array}$ & $\begin{array}{c}3.855 \\
(4.324)\end{array}$ \\
\hline Competition X Involvement & $\begin{array}{c}-1.633 \\
(2.487)\end{array}$ & $\begin{array}{c}-1.495 \\
(3.148)\end{array}$ \\
\hline Transfer & $\begin{array}{c}-0.572^{* * *} \\
(0.091)\end{array}$ & $\begin{array}{c}-0.667^{* * *} \\
(0.110)\end{array}$ \\
\hline Period & $\begin{array}{c}-0.409^{* *} \\
(0.153)\end{array}$ & $\begin{array}{c}-0.444^{* *} \\
(0.174)\end{array}$ \\
\hline Constant & $\begin{array}{l}22.607^{* * *} \\
(2.530)\end{array}$ & $\begin{array}{l}25.720^{* * *} \\
(3.287)\end{array}$ \\
\hline$R^{2} /$ Pseudo $R^{2}$ & 0.101 & 0.014 \\
\hline Observations & 1680 & 1680 \\
\hline Censored observations & & 242 \\
\hline Clusters & 21 & 21 \\
\hline
\end{tabular}

${ }^{*} p<.10,{ }^{* *} p<.05,{ }^{* * *} p<.01$

Notes: Robust standard errors, clustered by session, are in parentheses. The dependent variable is the number of punishment points assigned to the buyer. The Tobit regression is right-censored at the maximum possible punishment of 50. Only decisions from B type sellers are considered. Data from the symmetric access treatment are excluded as there is one seller type only. Wald tests after OLS estimation show that the effect of competition is not significant anymore in the intense competition treatment $(p>.10)$, but it is significant in the involvement treatment $(p<.01)$.

sign of the coefficient for the interaction of "Female" and "Competition." Moreover, the negative sign of the "Female" dummy reveals that women punish less than men in general. Regression (4) shows that these results also hold when we control for a number of personality dimensions that are potentially correlated with gender. ${ }^{21}$ We did not anticipate this gender effect ex-ante, and it should thus be interpreted cautiously. However, the finding that the punishment reducing effect of competition is less pronounced for women than for men nicely resonates with the existing literature showing that women tend to be more reluctant than men to enter into competitive environments (e.g., Niederle \& Vesterlund, 2007).

\footnotetext{
${ }^{21}$ None of the personality measures included in Model 4 in Table 5 shows a significant interaction with the competition dummy. Moreover, the interaction between competition and gender remains significant when we include these additional interaction terms in the regression.
} 
Table 5: Individual heterogeneity in sellers' punishment of the buyer

\begin{tabular}{|c|c|c|c|c|}
\hline & \multicolumn{4}{|c|}{ DV: Punishment for A } \\
\hline & $(1)$ & $(2)$ & (3) & $(4)$ \\
\hline & & & & OLS \\
\hline Competition & $\begin{array}{c}-8.951^{* * *} \\
(0.856)\end{array}$ & $\begin{array}{c}-9.908^{* * *} \\
(0.794)\end{array}$ & $\begin{array}{c}-11.852^{* * *} \\
(1.097)\end{array}$ & $\begin{array}{c}-11.746^{* * *} \\
(1.058)\end{array}$ \\
\hline Transfer & $\begin{array}{c}-0.418^{* * *} \\
(0.054)\end{array}$ & $\begin{array}{c}-0.543^{* * *} \\
(0.046)\end{array}$ & $\begin{array}{c}-0.426^{* * *} \\
(0.052)\end{array}$ & $\begin{array}{c}-0.411^{* * *} \\
(0.048)\end{array}$ \\
\hline Period & $\begin{array}{c}-0.355^{* * *} \\
(0.074)\end{array}$ & $\begin{array}{c}-0.364^{* * *} \\
(0.078)\end{array}$ & $\begin{array}{c}-0.355^{* * *} \\
(0.073)\end{array}$ & $\begin{array}{c}-0.355^{* * *} \\
(0.074)\end{array}$ \\
\hline Female & & & $\begin{array}{c}-3.942^{* *} \\
(1.455)\end{array}$ & $\begin{array}{c}-3.928^{* *} \\
(1.498)\end{array}$ \\
\hline Female X Competition & & & $\begin{array}{l}5.646^{* * *} \\
(1.428)\end{array}$ & $\begin{array}{l}5.782^{* * *} \\
(1.393)\end{array}$ \\
\hline Agreeableness & & & & $\begin{array}{c}-1.738 \\
(1.154)\end{array}$ \\
\hline Extraversion & & & & $\begin{array}{c}-0.124 \\
(0.671)\end{array}$ \\
\hline Intellect & & & & $\begin{array}{r}-1.894^{*} \\
(0.949)\end{array}$ \\
\hline Neuroticism & & & & $\begin{array}{c}0.924 \\
(0.908)\end{array}$ \\
\hline Conscientiousness & & & & $\begin{array}{c}0.837 \\
(0.811)\end{array}$ \\
\hline Constant & $\begin{array}{l}19.084^{* * *} \\
(1.222)\end{array}$ & $\begin{array}{l}19.881^{* * *} \\
(0.574)\end{array}$ & $\begin{array}{l}21.159^{* * *} \\
(1.319)\end{array}$ & $\begin{array}{l}30.090^{* * *} \\
(7.473)\end{array}$ \\
\hline Individual fixed effects & No & Yes & No & No \\
\hline$R^{2}$ & 0.061 & 0.578 & 0.068 & 0.081 \\
\hline Observations & 5100 & 5100 & 5100 & 5100 \\
\hline Clusters & 28 & 28 & 28 & 28 \\
\hline
\end{tabular}

${ }^{*} p<.10,{ }^{* *} p<.05,{ }^{* * *} p<.01$

Notes: Robust standard errors, clustered by session, are in parentheses. The dependent variable is the number of punishment points assigned to the buyer. Big Five traits included in model 4 were measured in the post-experimental questionnaire using a German translation (Streib \& Wiedmaier, 2001) of the mini-IPIP scale (Donnellan et al., 2006). Each trait was measured by four items on five-point Likert scales. Cronbach's $\alpha$ indicate the following measurement reliabilities: Agreeableness $\alpha=.650$, Extraversion $\alpha=.734$, Intellect $\alpha=.636$, Conscientiousness $\alpha=.756$, and Neuroticism $\alpha=.689$

\subsection{Buyers' Profits and Choice of Procedure}

The fact that the choice of competition reduces the punishment that sellers inflict on the buyer (for a given transfer level) renders competition potentially attractive for buyers. However, giving up authority and delegating the transfer determination to a competitive auction 
also means that the buyer loses control over the resulting transfer. In this section we therefore examine the impact of the buyer's choice of procedure on profits.

Figure 4 allows identifying the optimal strategy for a money-maximizing buyer. The grey line shows the average profit of the buyer as a function of the transfer that the buyer chooses under authority. The black line illustrates the expected profit when the buyer chooses competition; it is horizontal because the buyer can no longer control the transfer level but instead simply faces the expected competition outcome. The figure reveals that buyers cannot realize higher (expected) profits when they choose authority instead of competition. Buyers can maximize their expected profit either by using competition or by setting directly a small transfer, slightly greater than zero. When the buyers chose authority, the observed average transfers were indeed in the profit-maximizing range; they amount to 3.69, 3.33, 4.79, and 6.53 in the baseline, intense competition, symmetric access, and involvement treatments, respectively. ${ }^{22}$

Buyers choose competition with increasing frequency over the course of the 12 periods of the experiment. While less than 40 percent of buyers make use of competition in the first three periods of the experiment, they learn quickly that choosing competition can be beneficial, and the share of buyers who use competition increases to levels above 50 percent in the last three periods. ${ }^{23}$ On average over all treatments and periods, buyers choose competition in 44.2 percent of all cases. ${ }^{24}$

\section{Conclusions}

This paper provides a new perspective on the impact of competitive procedures on economic outcomes. We show that the use of competition affects, as such, how people judge the fairness of resulting monetary allocations. Understanding fairness perceptions is economically relevant because many people are willing to sacrifice resources to punish violations of fairness norms. If a seller has no choice but to accept unfavorable terms of trade, be it due to competitive pressure or because the buyer has the authority to dictate these terms, the seller might want to inflict damage on the buyer, e.g., by reducing quality or effort. Such

\footnotetext{
${ }^{22}$ The average direct transfer is marginally significantly higher in the involvement treatment than in the baseline $(p=.060)$ and in the intense competition treatment $(p=.057)$, but all other comparisons are not significant (p-values from OLS regression clustered by session).

${ }^{23}$ The positive time trend in the choice of competition across periods is significant in the baseline $(p<.01)$, the intense competition treatment $(p<.01)$, and the involvement treatment $(p=.029)$, but non-significant in the symmetric access treatment $(p=.104$; $\mathrm{p}$-values from OLS regression clustered by session).

${ }^{24}$ Competition is chosen in $48.3,39.2,43.1$, and 46.4 percent in the baseline, intense competition, symmetric access, and involvement treatment, respectively. An OLS regression, clustered by session, shows that these frequencies are not significantly different from each other.
} 
Figure 4: Buyers' profits by choice of procedure

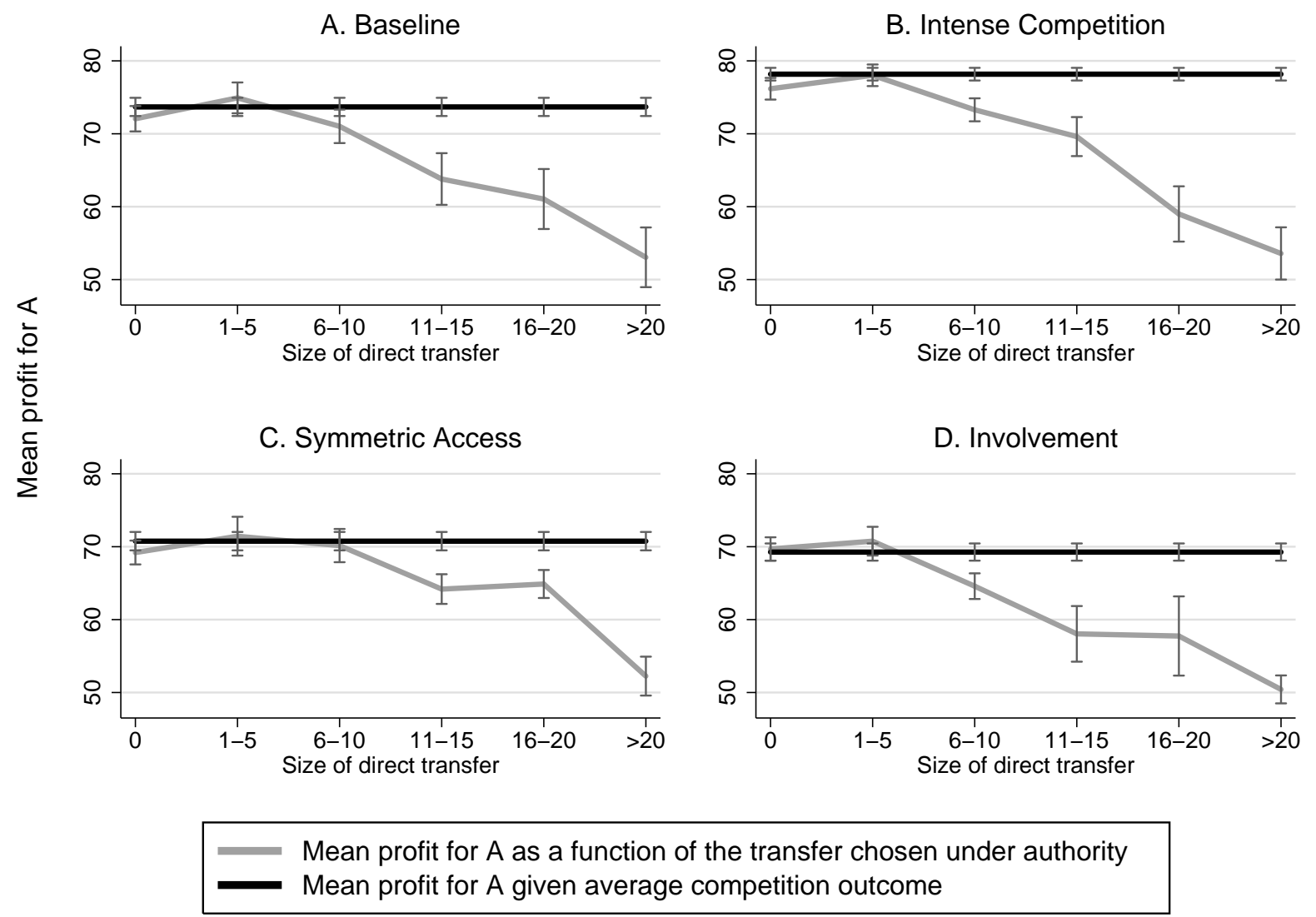

Notes: Error bars represent plus/minus one standard error of the mean, clustered by individual.

counterproductive behaviors can cause substantial deadweight losses.

The main result of this paper is that - relative to using authority - the use of competitive procedures reduces counterproductive behavior in response to unequal distributive outcomes. We show that a powerful trading party, who could simply dictate the terms of trade, can deflect the blame for unequal outcomes by letting the market decide, i.e., by delegating the determination of the terms of trade to a competitive procedure.

Our findings have implications for the organization of trade relationships. For example, a producer in need of inputs from suppliers may be well advised to set up competitive procurement auctions even if there is no asymmetric information regarding the suppliers' production costs and the producer would be powerful enough to dictate prices. The reason is that the same prices are likely to trigger fewer counterproductive reactions if they are determined competitively rather than imposed by authority.

Our study also adds a new angle to the discussion of transaction costs in the incomplete contracting literature. Existing work emphasizes the trade-off between hold-up prob- 
lems in competitive market relations and bureaucracy costs within authority-based firms (Williamson 1975, 1985). Our paper reveals another possible downside of authority that has - to the best of our knowledge - not been considered before: replacing a competitive price determination with fiat may trigger retaliatory actions from trading partners that would not have occurred to this extent in the market environment.

Finally, it is worth emphasizing some limitations and possible extensions of our work. First, our paper investigates how (potential) trading partners react depending on whether a powerful party chooses competition or authority to determine the terms of trade. While situations involving a large power differential and very unequal outcomes, as implemented by our experiments, are of particular interest in this context, it would also be of importance to better understand the role of competition in more balanced relations. In these cases, the possible alternative to a competitive procedure would be bilateral bargaining rather than authority. Second, in this study we focus exclusively on counterproductive behavior and retaliatory actions. In some situations, however, efficient trade not only necessitates limiting harmful behavior, but also requires inducing voluntary cooperation. It would be very interesting to examine whether the use of competition also allows motivating trading partners to engage in helpful behavior. We leave these interesting extensions for future research. 


\section{References}

Bartling, B. \& Fischbacher, U. (2012). Shifting the blame: On delegation and responsibility. Review of Economic Studies, 79(1), 67-87.

Bartling, B. \& Schmidt, K. M. (2014). Reference points, social norms, and fairness in contract renegotiations. Journal of the European Economic Association, forthcoming.

Besley, T. (2013). What's the good of the market? An essay on Michael Sandel's what money can't buy. Journal of Economic Literature, 51 (2), 478-495.

Bolton, G. E., Brandts, J., \& Ockenfels, A. (2005). Fair procedures: Evidence from games involving lotteries. Economic Journal, 115(506), 1054-1076.

Bolton, G. E. \& Ockenfels, A. (2000). ERC: A theory of equity, reciprocity, and competition. American Economic Review, 166-193.

Camerer, C. (2003). Behavioral game theory: Experiments in strategic interaction. Princeton University Press.

Cappelen, A. W., Konow, J., Sørensen, E. Ø., \& Tungodden, B. (2013). Just luck: An experimental study of risk-taking and fairness. American Economic Review, 103(4), 13981413.

Coffman, L. C. (2011). Intermediation reduces punishment (and reward). American Economic Journal: Microeconomics, 3(4), 77-106.

Dana, J., Weber, R. A., \& Kuang, J. X. (2007). Exploiting moral wiggle room: Experiments demonstrating an illusory preference for fairness. Economic Theory, 33(1), 67-80.

Darley, J. M. \& Latane, B. (1968). Bystander intervention in emergencies: diffusion of responsibility. Journal of Personality and Social Psychology, 8(4), 377.

Donnellan, M. B., Oswald, F. L., Baird, B. M., \& Lucas, R. E. (2006). The mini-IPIP scales: Tiny-yet-effective measures of the Big Five factors of personality. Psychological Assessment, 18(2), 192-203.

Dufwenberg, M. \& Kirchsteiger, G. (2004). A theory of sequential reciprocity. Games and Economic Behavior, 47(2), 268-298.

Falk, A. \& Fischbacher, U. (2006). A theory of reciprocity. Games and Economic Behavior, $54(2), 293-315$. 
Falk, A. \& Szech, N. (2013). Morals and markets. Science, 340(6133), 707-711.

Fehr, E. \& Fischbacher, U. (2003). The nature of human altruism. Nature, 425(6960), 785-791.

Fehr, E., Hart, O., \& Zehnder, C. (2009). Contracts, reference points, and competition behavioral effects of the fundamental transformation. Journal of the European Economic Association, 7(2-3), 561-572.

Fehr, E., Hart, O., \& Zehnder, C. (2011). Contracts as reference points - experimental evidence. American Economic Review, 101 (2), 493-525.

Fehr, E. \& Schmidt, K. M. (1999). A theory of fairness, competition, and cooperation. Quarterly Journal of Economics, 114(3), 817-868.

Fischbacher, U. (2007). z-Tree: Zurich toolbox for ready-made economic experiments. Experimental Economics, 10(2), 171-178.

Fischbacher, U., Fong, C. M., \& Fehr, E. (2009). Fairness, errors and the power of competition. Journal of Economic Behavior \&3 Organization, 72(1), 527-545.

Gächter, S., Renner, E., \& Sefton, M. (2008). The long-run benefits of punishment. Science, 322(5907), 1510-1510.

Greiner, B. (2003). An online recruitment system for economic experiments. In K. Kremer \& V. Macho (Eds.), Forschung und wissenschaftliches Rechnen 2003 GWDG Bericht, volume 63 (pp. 79-93). Goettingen: Ges. f. Wiss. Datenverarbeitung.

Grosskopf, B. (2003). Reinforcement and directional learning in the ultimatum game with responder competition. Experimental Economics, 6(2), 141-158.

Güth, W., Marchand, N., \& Rullière, J.-L. (1998). Equilibration and context dependency: An experimental investigation of the ultmatum bargaining game. Revue économique, 785794.

Hamman, J. R., Loewenstein, G., \& Weber, R. A. (2010). Self-interest through delegation: An additional rationale for the principal-agent relationship. American Economic Review, $100(4), 1826-1846$.

Hart, O. \& Moore, J. H. (2008). Contracts as reference points. Quarterly Journal of Economics, 123(1), 1-48. 
Kahneman, D., Knetsch, J. L., \& Thaler, R. (1986). Fairness as a constraint on profit seeking: Entitlements in the market. American Economic Review, 728-741.

Klemperer, P. (1999). Auction theory: A guide to the literature. Journal of Economic Surveys, 13(3), 227-286.

Marchand, N. (2001). Envy and reciprocity in a competitive ultimatum game - an experimental investigation. Revue d'économie politique, 111(1), 95-119.

Niederle, M. \& Vesterlund, L. (2007). Do women shy away from competition? Do men compete too much? Quarterly Journal of Economics, 122(3), 1067-1101.

Nikiforakis, N. (2008). Punishment and counter-punishment in public good games: Can we really govern ourselves? Journal of Public Economics, 92, 91-112.

Piketty, T. (2014). Capital in the Twenty-First Century. Harvard University Press.

Rabin, M. (1993). Incorporating fairness into game theory and economics. American Economic Review, 1281-1302.

Roth, A. E., Prasnikar, V., Okuno-Fujiwara, M., \& Zamir, S. (1991). Bargaining and market behavior in Jerusalem, Ljubljana, Pittsburgh, and Tokyo: An experimental study. American Economic Review, 1068-1095.

Sandel, M. J. (2012). What Money Can't Buy - The Moral Limits of Markets. Penguin.

Streib, H. \& Wiedmaier, M. (2001). IPIP Five Factors 100 item version - German translation. Forschungsstelle Biographische Religionsforschung, University of Bielefeld.

Thibaut, J. W. \& Walker, L. (1975). Procedural justice: A psychological analysis. Hillsdale, NJ: Erlbaum.

Williamson, O. E. (1975). Markets and Hierarchies: Analysis and Antitrust Implications. New York: The Free Press.

Williamson, O. E. (1985). The Economic Intstitutions of Capitalism. New York: Simon and Schuster. 


\section{Appendix [For Online Publication]}

\section{A Two-Part Models}

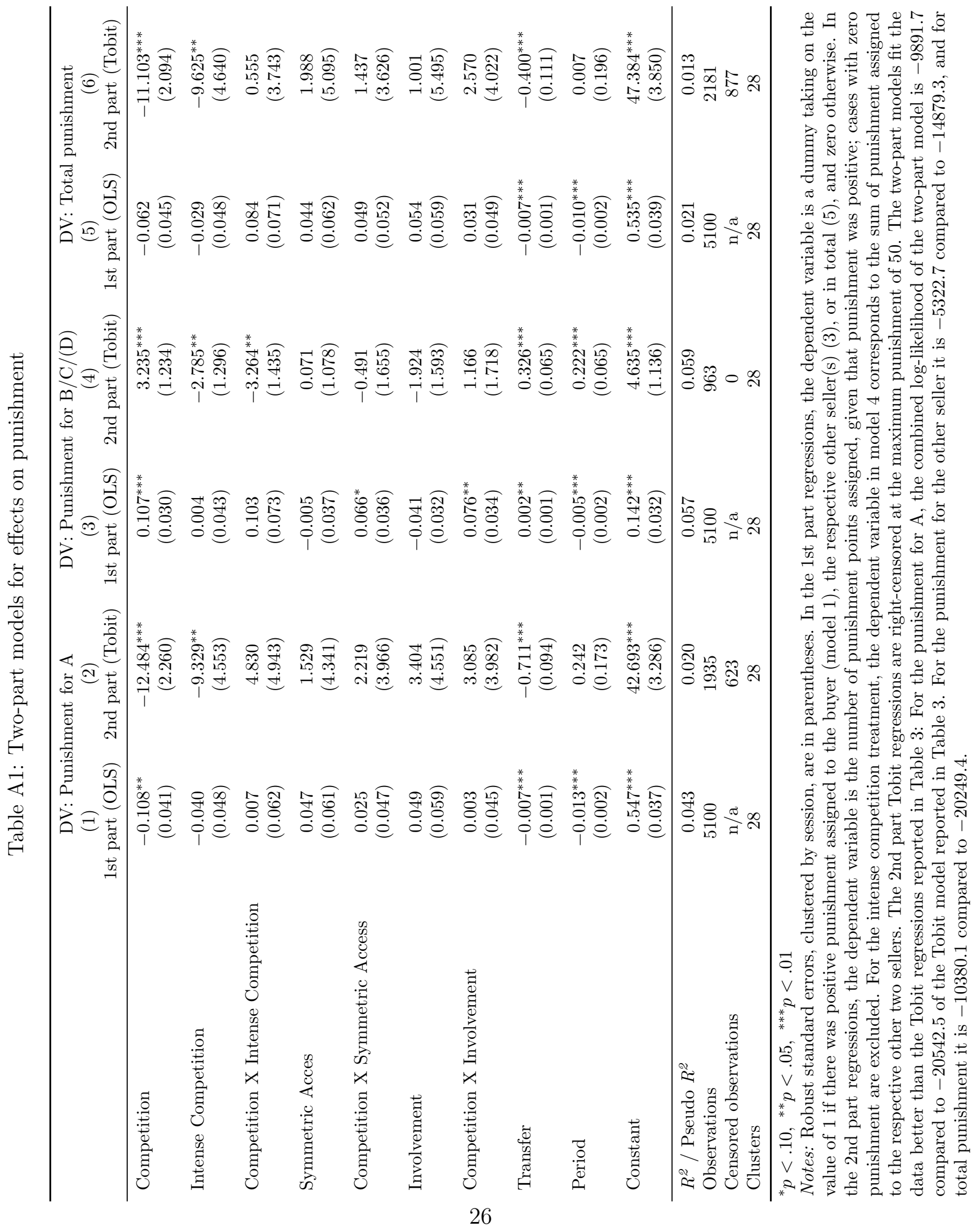




\section{B Predictive Power of Different Punishment Motives}

In this appendix we explore the extent to which different punishment motives that have previously been discussed in the literature can explain the punishment pattern we observe in the experiment:

1. For a given transfer, the punishment for $\mathrm{A}$ is lower under competition than under authority.

1.a Both $\mathrm{B}$ and $\mathrm{C}$ punish $\mathrm{A}$ less under competition than under authority (holding the transfer constant).

1.b The punishment for A decreases in the transfer level.

2. For a given transfer, the punishment for the other seller is higher under competition than under authority.

2.a The increase in the punishment for the other seller under competition is driven by the fact that the losers in the competitive auction punish the winners.

2.b The punishment for the other seller increases in the transfer level.

3. For a given transfer, total punishment is lower under competition than under authority.

Since we study costly punishment in one-shot interactions, models assuming pure self-interest cannot explain positive punishments in our setup. We therefore derive predictions using four alternative motives: outcome-based fairness, intention-based reciprocity, attribution of responsibility, and the perception of competition as a fair procedure. We consciously try to reduce each motive to its essence and formalize them in the most simple and stylized way we could think of. For each motive we define a measure of a player's punishment inclination in each situation that can occur in the experiment. To facilitate the comparison of the predictive power of the different motives, we formalize them as fully nested models, i.e., we determine the underlying punishment inclination based on the outcome-based fairness approach and implement the other three motives as simple weighting functions.

Tables B1 and B2, and Figure B1 provide detailed illustrations of the punishment pattern predicted by each of the four motives. The top part of Table B1 displays the punishment inclinations predicted by the outcome-based fairness approach. The bottom part of Table B1 displays the punishment inclinations generated by the other three motives. The punishment inclinations predicted by intention-based reciprocity, responsibility attribution, and

the perception of competition as a fair procedure are obtained by simply multiplying the punishment inclinations predicted by the outcome-based approach with the corresponding 
weighting function. The weights are summarized in Table B2. In what follows, we introduce and explain each model briefly, and discuss in how far the predicted behavior corresponds to the actually observed behavior. For reasons of simplicity, we restrict attention to our baseline treatment and do not go into the details of how our treatment variations affect the punishment predictions.

\section{B.1 Outcome-Based Fairness}

Theories of outcome-based fairness (e.g., Fehr \& Schmidt, 1999; Bolton \& Ockenfels, 2000) assume that decision makers experience a disutility if their own payoff differs from the payoffs of other players in their reference group. In our environment these models have predictive power, because punishing a player who is better off allows reducing disadvantageous payoff inequality. We implement the punishment inclination triggered by outcome-based fairness as a linear function of disadvantageous payoff inequality. Disadvantageous payoff inequality is maximized if a player receives no transfer (or a transfer of 0 ). In this case the sum of differences between the punisher's own payoff and the other two players' payoffs is equal to 80 (punishment prediction $=1$ ). Smaller payoff inequalities reduce the punishment prediction proportionally. ${ }^{25}$ Formally, the outcome-based punishment inclination $\rho_{i}^{j}$ of player $i$ targeted at player $j, i \neq j$, is thus defined by:

$$
\rho_{i}^{j}=\frac{\max \left(x_{j}-x_{i}, 0\right)}{80}
$$

where $x_{i}$ and $x_{j}$ represent the payoffs of the corresponding player. The inequality is divided by the maximally possible inequality $(80)$ to normalize the measure to the range between 0 and 1.

The top part of Table B1 provides details on the punishment intensities predicted by a model of purely outcome-based fairness. The table reveals that outcome-based fairness fails to predict our three main results (Results 1-3). As punishment is solely determined by outcomes, outcome-based fairness cannot explain why the same transfer triggers different punishment inclinations depending on the procedure chosen to determine the transfer (see also Panel A of Figure B1). However, the outcome-based measure captures correctly that the punishment for A decreases in the transfer (Result 1.b), while the punishment for the other seller increases in the transfer (Result 2.b). Moreover, the outcome-based measure is

\footnotetext{
${ }^{25}$ If there are disadvantageous payoff inequalities relative to both other players and the payoff inequalities cannot be completely eliminated, linear inequality aversion does not predict how the punisher will allocate his punishment points to the other two players. Our measure assumes that the punisher allocates punishment points proportionally to the relative size of the corresponding inequality.
} 
also in line with the fact that sellers' mutual punishments are driven by the seller who lost the competitive auction (Result 2.a).

Table B1: Players' punishment inclinations according to different motives

\begin{tabular}{|c|c|c|c|c|c|c|c|c|c|c|}
\hline \multirow[b]{3}{*}{ Model } & \multirow[b]{3}{*}{ Punisher } & \multicolumn{3}{|c|}{ Authority } & \multicolumn{6}{|c|}{ Competition } \\
\hline & & & & & & B wins & & & $\mathrm{C}$ wins & \\
\hline & & $\mathbf{A}$ & $\mathrm{B} / \mathrm{C}$ & Total & $\mathbf{A}$ & $\mathrm{B} / \mathrm{C}$ & Total & $\mathbf{A}$ & $\mathrm{B} / \mathrm{C}$ & Total \\
\hline Outcome- & $\mathrm{B}$ & $\frac{80-2 t}{80}$ & 0 & $\frac{80-2 t}{80}$ & $\frac{80-2 t}{80}$ & 0 & $\frac{80-2 t}{80}$ & $\frac{80-t}{80}$ & $\frac{t}{80}$ & 1 \\
\hline Based & $\mathrm{C}$ & $\frac{80-t}{80}$ & $\frac{t}{80}$ & 1 & $\frac{80-t}{80}$ & $\frac{t}{80}$ & 1 & $\frac{80-2 t}{80}$ & 0 & $\frac{80-2 t}{80}$ \\
\hline Intention-Based & $\mathrm{B}$ & $\frac{80-2 t}{80}$ & 0 & $\frac{80-2 t}{80}$ & $\frac{80-2 t}{80}$ & 0 & $\frac{80-2 t}{80}$ & $\frac{80-t}{80}$ & $\frac{0.5 t}{80}$ & $\frac{80-0.5 t}{80}$ \\
\hline Reciprocity & $\mathrm{C}$ & $\frac{80-t}{80}$ & 0 & $\frac{80-t}{80}$ & 0 & $\frac{0.5 t}{80}$ & $\frac{0.5 t}{80}$ & 0 & 0 & 0 \\
\hline Responsibility- & B & $\frac{80-2 t}{80}$ & 0 & $\frac{80-2 t}{80}$ & $\frac{40-t}{80}$ & 0 & $\frac{40-t}{80}$ & $\frac{40-0.5 t}{80}$ & $\frac{0.5 t}{80}$ & 0.5 \\
\hline Attribution & $\mathrm{C}$ & $\frac{80-t}{80}$ & 0 & $\frac{80-t}{80}$ & $\frac{40-0.5 t}{80}$ & $\frac{0.5 t}{80}$ & 0.5 & $\frac{40-t}{80}$ & 0 & $\frac{40-t}{80}$ \\
\hline Fair & B & $\frac{80-2 t}{80}$ & 0 & $\frac{80-2 t}{80}$ & $\frac{40-t}{80}$ & 0 & $\frac{40-t}{80}$ & $\frac{40-0.5 t}{80}$ & $\frac{0.5 t}{80}$ & 0.5 \\
\hline Competition & $\mathrm{C}$ & $\frac{80-t}{80}$ & $\frac{t}{80}$ & 1 & $\frac{40-0.5 t}{80}$ & $\frac{0.5 t}{80}$ & 0.5 & $\frac{40-t}{80}$ & 0 & $\frac{40-t}{80}$ \\
\hline
\end{tabular}

Notes: $t$ stands for the transfer from A to the receiving seller (B or $\mathrm{C}$ ). The columns indicate the player at which punishment is targeted, the rows indicate the player at the origin of the punishment. The top of the table displays the punishment inclinations of $\mathrm{B}$ and $\mathrm{C}$ towards $\mathrm{A}$ and the other seller $(\mathrm{B} / \mathrm{C})$ in the baseline treatment according to an outcome-based fairness model. For the outcome-based model, we assume that a player's punishment inclination towards another player is a linear function of the disadvantageous inequality that the punisher experiences relative to the other player. We normalize the measure by dividing the experienced inequality by the maximally possible disadvantageous inequality of 80 . The bottom of the table shows the punishment inclinations in the alternative models that result from multiplying the punishment inclinations defined in the outcome-based model with the weighting factors summarized in Table B2.

We now turn to the other three punishment motives. We model each one of them as a weighting function $\eta$ which transforms the punishment intensities predicted by the outcomebased approach. For every alternative model we consider, the punishment inclination of player $i$ towards player $j, i \neq j$, is therefore defined by:

$$
\rho_{i}^{j}=\eta \times \frac{\max \left(x_{j}-x_{i}, 0\right)}{80}
$$

Table B2 summarizes the weighting functions $\eta$ for all alternative models. We discuss the derivation of these weights and the resulting punishment predictions for each alternative model below. 
Figure B1: Predicted and observed punishment patterns by procedure and transfer size

\section{Model Predictions}
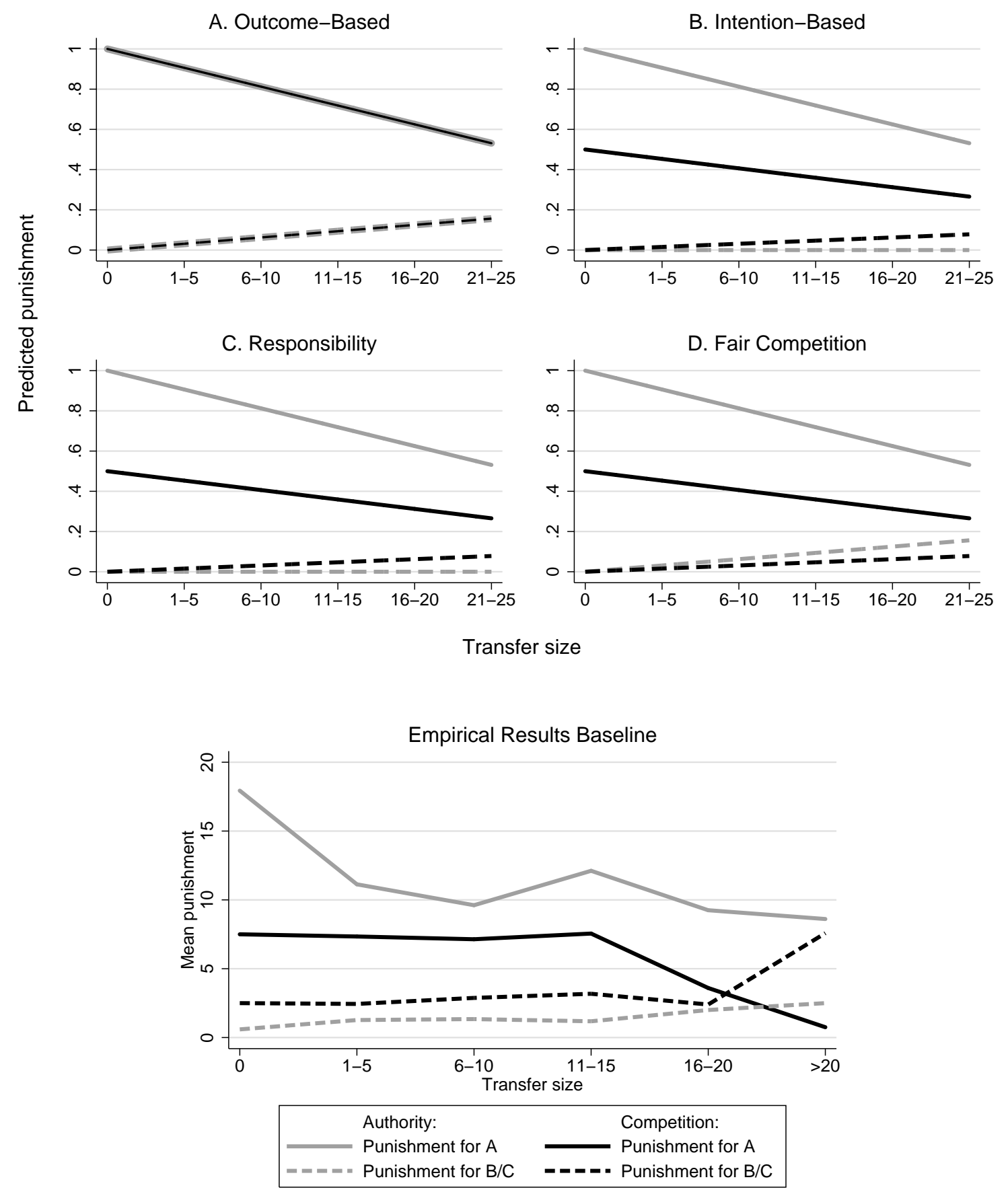

Notes: In the figure, the punishment inclination is averaged across the two seller types in the experiment. This is why the predictions of the intention-based (Panel B) and the responsibility model (Panel C) are identical. The different predictions of the two models for the different types can be seen in Table B1. 
Table B2: Weighting factors for punishment inclinations in alternative fairness models

\begin{tabular}{|cc|cc|cc|ccc|}
\hline & & Authority & \multicolumn{4}{|c|}{ Competition } \\
Model & Punisher & A & B /C & A & B $/$ C & A & A & B/C \\
\hline Intention-Based & B & 1 & & 1 & & 1 & 0.5 \\
Reciprocity & C & 1 & 0 & 0 & 0.5 & 0 & \\
\hline Responsibility & B & 1 & 0 & 0.5 & 0.5 & 0.5 & 0.5 \\
Attribution & C & 1 & 0 & 0.5 & 0.5 & 0.5 & 0.5 \\
\hline Fair & B & 1 & 1 & 0.5 & 0.5 & 0.5 & 0.5 \\
Competition & C & 1 & 1 & 0.5 & 0.5 & 0.5 & 0.5 \\
\hline
\end{tabular}

Notes: The table displays the weighting factors $\eta$ for punishment inclinations of $\mathrm{B}$ and $\mathrm{C}$ towards $\mathrm{A}$ and the other seller $(\mathrm{B} / \mathrm{C})$ in the baseline treatment. The weights are relative to the punishment inclinations of the outcome-based fairness model defined in the top part of Table B1. The columns indicate the player at which punishment is targeted, the rows indicate the player at the origin of the punishment.

\section{B.2 Intention-Based Reciprocity}

A critical difference between the purely outcome-based approach and theories of intentionbased reciprocity is that the perceived unfairness of an outcome does not only depend on the realized payoffs, but also on available, but not chosen alternatives (Rabin, 1993; Falk \& Fischbacher, 2006; Dufwenberg \& Kirchsteiger, 2004). Inspired by the model of Falk \& Fischbacher (2006), we assume that the degree to which players suffer from inequality depends on whether the inequality has been caused by an unkind act of another player or not. Suppose that a decision is perceived as "fully" unkind if another player has created the unequal allocation although he could have avoided or at least reduced the inequality without creating disadvantageous inequality for himself. If the other player could only have avoided or reduced the inequality by accepting a disadvantageous situation for himself, the decision is perceived as "partially" unkind. In cases in which the other player had no possibility to avoid the inequality, the decision is not perceived as unkind at all. The degree of unkindness therefore determines whether and how strongly disadvantageous inequality creates an inclination to punish.

We operationalize these ideas as follows: Fully unkind decisions trigger the full punishment inclination justified by the inequality (i.e., $\eta=1$ ). In our baseline treatment, A always has the possibility to choose authority and to transfer the maximum possible amount to B, which would equalize payoffs between A and B. Hence, if A chooses not to do so, the resulting inequality between $\mathrm{A}$ and $\mathrm{B}$ is always perceived as fully unkind by $\mathrm{B}$. The same is true for the inequality between A and C if A chooses authority. Since A could have chosen competition, which would have opened up the possibility for $\mathrm{C}$ to obtain a positive transfer, the choice of 
authority is perceived as fully unkind by C. Choosing competition in contrast is the kindest action of $\mathrm{A}$ towards $\mathrm{C}$ (in expectation this is true independently of the realized transfer and of whether $\mathrm{C}$ eventually gets the transfer or not), and should therefore not trigger any punishment for A by $\mathrm{C}(\eta=0)$. Finally, we assume that partially unkind decisions trigger half the punishment inclination of fully unkind decisions (i.e., $\eta=0.5$, this corresponds to $\epsilon$ in the notation used by Falk \& Fischbacher 2006). In our case, the inequality that exists between the two sellers after the competitive procedure is perceived as partially unkind by the seller who lost the auction. The auction winner could only have avoided this inequality

by clicking later (or not clicking at all), and thus accepting a disadvantageous outcome for himself.

At the aggregate level, intention-based reciprocity predicts our three main results (see Panel B of Figure B1): The punishment for A is lower under competition than under authority (Result 1), while the punishment for the respective other seller is higher (Result 2). The measure also correctly predicts lower total punishment under competition (Result 3), because the decrease in the punishment for $\mathrm{A}$ is clearly smaller than the increase in the punishment for the respective other seller. However, a closer inspection of Table B1 reveals that the underlying forces behind the aggregate effects are only partially in line with the data. While the intention-based measure captures that the increase in the punishment of the respective other seller stems from the fact that the auction loser punishes the winner (Result 2a), it also predicts that the decrease in the punishment for A exclusively stems from the fact that $\mathrm{C}$ never punishes $\mathrm{A}$ if she chooses competition. This clearly contradicts our observation that both $\mathrm{B}$ and $\mathrm{C}$ punish less under the competitive procedure (Result 1.a).

\section{B.3 Attribution of Responsibility}

Bartling \& Fischbacher (2012) introduce a model in which a player's inclination to punish a specific other player depends on the extent to which this other player is held responsible for the unequal outcome. We implement this notion in a very simple way. We assume that a punisher assigns equal responsibility to all other players who have been actively involved in the decision making process that led to an unequal outcome. This implies the following responsibility attributions in our setup: Under authority only A makes a choice. Accordingly, A carries the full responsibility for the inequality that exists between her and each seller $(\eta=1)$. B, on the other hand, does not carry any responsibility for the inequality that exists between him and $\mathrm{C}(\eta=0)$. Under competition A (who chooses the procedure) and the two sellers participating in the auction are all involved in the decision making process. From the perspective of the punishing player ( $\mathrm{B}$ or $\mathrm{C}$ ) both $\mathrm{A}$ and the respective other seller 
are therefore to be blamed if a disadvantageous inequality results. Hence each one of them is held responsible for one half of the realized disadvantageous inequalities (i.e., $\eta=0.5$ for each of them). ${ }^{26}$

The responsibility measure is in line with our three main results listed above (Results 1-3, see Table B1 and Panel C of Figure B1). Furthermore, it also predicts that both B and $\mathrm{C}$ punish A less under competition than under authority (Result 1.a). The measure also captures the observation that the increase in the sellers' mutual punishments under competition is caused by auction losers who punish winners (Result 2.a). Thus, at least qualitatively, the responsibility model delivers a good description of the punishment pattern observed in our experiment.

\section{B.4 Competition as a Fair Procedure}

Finally, we also consider the possibility that people simply consider competitively determined outcomes as fair (see e.g., Hart \& Moore, 2008, for arguments along these lines). We implement the idea that competition is perceived as a fair procedure by assuming that people suffer less from disadvantageous inequality if the payoffs have been determined competitively. Specifically, we suppose that the punishment inclination is divided by two under competition (i.e., $\eta=0.5$ if a transfer has been determined under competition).

While the concept of competition as a fair procedure can explain why A receives less punishment for the same transfer if she chooses to let the transfer be determined competitively (Result 1), the approach fails to explain the increase in mutual punishment of the sellers under the competitive procedure (Result 2).

\section{B.5 Econometric Comparison of Different Motives}

The discussion above seems to suggest that, qualitatively, the responsibility attribution measure best explains the punishment pattern that we observe in the experiment. However, Table B3 reveals that a quantitative analysis does not provide further support for this conclusion. The table reports a set of OLS estimations in which we regress the sellers' punish-

\footnotetext{
${ }^{26}$ This implementation of the responsibility model as a nested version of the outcome-based model means that part of the punishment inclination triggered by inequality disappears if the respective player is not held fully responsible for the outcome. We think it is natural to interpret this effect as "diffusion of responsibility." Alternatively, however, responsibility attribution could also be implemented such that the full punishment inclination is distributed across different players. For example, under competition not only A is punished for the inequality between $\mathrm{A}$ and $\mathrm{C}$, but also B (because each one of them carries half of the responsibility for this outcome). In this alternative model responsibility would not be diffused, but reassigned. While we think that such a model is interesting, we decided to use the simpler, nested model to facilitate the model comparisons. However, we also derived predictions for the alternative model (not reported in the paper). The alternative model does not have superior predictive power.
} 
ment decisions (targeting both $\mathrm{A}$ and the respective other seller) on our four measures. Not surprisingly, the $R^{2}$ s of these regressions show that the explanatory power of outcome-based fairness is clearly lower than that of the other three measures. However, the predictive power of intention-based reciprocity, responsibility attribution, and a preference for competition is very similar. It is also noteworthy that all $R^{2}$ s are relatively low (i.e., no measure explains more than about 17 percent of the variance). This is not surprising given the large amount of indidvidual heterogeneity present in the data (see the discussion in section 4.4).

Table B3: Predictive power of punishment motives

\begin{tabular}{|c|c|c|c|c|}
\hline & $\begin{array}{l}(1) \\
\text { OLS }\end{array}$ & $\begin{array}{l}\text { Punishmen } \\
(2) \\
\text { OLS }\end{array}$ & $\begin{array}{l}\mathrm{A} \text { and } \mathrm{B} / \mathrm{C} \\
(3) \\
\text { OLS }\end{array}$ & $\begin{array}{l}(4) \\
\text { OLS }\end{array}$ \\
\hline Outcome-Based & $\begin{array}{l}11.911^{* * *} \\
(1.430)\end{array}$ & & & \\
\hline Intention-Based & & $\begin{array}{l}13.191^{* * *} \\
(1.662)\end{array}$ & & \\
\hline Responsibility & & & $\begin{array}{l}14.708^{* * *} \\
(1.787)\end{array}$ & \\
\hline Fair Competition & & & & $\begin{array}{l}14.856^{* * *} \\
(1.801)\end{array}$ \\
\hline Constant & $\begin{array}{l}1.016^{* * *} \\
(0.266)\end{array}$ & $\begin{array}{l}1.918^{* * *} \\
(0.380)\end{array}$ & $\begin{array}{l}1.384^{* * *} \\
(0.388)\end{array}$ & $\begin{array}{l}1.245^{* * *} \\
(0.389)\end{array}$ \\
\hline$R^{2}$ & 0.132 & 0.166 & 0.162 & 0.162 \\
\hline Observations & 2592 & 2592 & 2592 & 2592 \\
\hline Clusters & 108 & 108 & 108 & 108 \\
\hline
\end{tabular}




\section{Experimental Instructions (Baseline)}

General instructions for participants

We are pleased to welcome you to this economic study.

If you read the following instructions carefully you can - depending on your decisions and those of the other participants - earn money in addition to the $\mathbf{1 0}$ Euros you receive as an initial endowment. It is thus very important, that you read these instructions carefully. If you have questions, please address them to us.

Communication with other participants of this study is strictly forbidden during the study. Violation of this rule leads to exclusion from the study and from all payments.

During the study, we will not speak of Euros, but of points. Your entire earnings will thus be first calculated in points. The points you earn during the study will be converted to Euros at the end of the study, where the following exchange rate applies:

\section{Points = 1 Euro.}

At the end of the study, we will pay you the point amount you earn during the study plus 10 Euros for showing up in cash.

We will explain the exact procedure of the study on the following pages. 


\section{The study}

The study lasts for 12 periods. At the beginning of each period, two other participants will be randomly assigned to you. This assignment takes place anew each period. This means that the same participants are not assigned to you in the individual periods. You will neither learn of the identity of the persons assigned to you before nor after the study. The persons assigned to you will also not learn of your identity.

There are three types of participants in this study: participants A, B, and C. In each period, a participant $\mathrm{A}$, a participant $\mathrm{B}$ and a participant $\mathrm{C}$ are assigned to each other. You are a participant A / B / C for the entire duration of the study.

All participants with whom you interact during this study are sitting in this room.

\section{Participant A's decision on the distribution procedure}

In each period, participant $A$ can decide which procedure will be used to distribute 110 points between the three participants.

To do this, participant A can choose one of the following distribution procedures:

- The direct decision mechanism or

- The competitive mechanism.

Both procedures will be explained in more detail on the following pages.

\section{The direct decision mechanism}

In the direct decision mechanism, participant $\mathrm{A}$ decides him/herself how the 110 points will be divided between him/herself and the other two participants. The starting point is determined by the following distribution:

\begin{tabular}{|c|c|c|}
\hline $\begin{array}{c}\text { Points for } \\
\text { participant A }\end{array}$ & $\begin{array}{c}\text { Points for } \\
\text { participant B }\end{array}$ & $\begin{array}{c}\text { Points for } \\
\text { participant C }\end{array}$ \\
\hline $\mathbf{9 0}$ & $\mathbf{1 0}$ & $\mathbf{1 0}$ \\
\hline
\end{tabular}


Participant A can only change the distribution by transferring points to participant $B$. He or she can transfer between 0 and 40 points to participant B. Every point that participant A transfers to participant B increases participant B's payment by one point and at the same time reduces participant A's payment by one point.

Participant A cannot transfer points to participant $\mathrm{C}$, meaning that participant $\mathrm{C}$ always receives 10 points.

The following table indicates how participant A's transfer decision changes the final distribution of points:

\begin{tabular}{|c|c|c|c|}
\cline { 2 - 4 } \multicolumn{1}{c|}{} & $\begin{array}{c}\text { Points for } \\
\text { participant A }\end{array}$ & $\begin{array}{c}\text { Points for } \\
\text { participant B }\end{array}$ & $\begin{array}{c}\text { Points for } \\
\text { participant C }\end{array}$ \\
\hline Transfer to B =0 & $\mathbf{9 0}$ & $\mathbf{1 0}$ & $\mathbf{1 0}$ \\
\hline Transfer to B $=1$ & $\mathbf{8 9}$ & $\mathbf{1 1}$ & $\mathbf{1 0}$ \\
\hline Transfer to B $=2$ & $\mathbf{8 8}$ & $\mathbf{1 2}$ & $\mathbf{1 0}$ \\
\hline Transfer to B $=3$ & $\mathbf{8 7}$ & $\mathbf{1 3}$ & $\mathbf{1 0}$ \\
\hline$\ldots$ & $\ldots$ & $\ldots$ & $\ldots$ \\
\hline Transfer to B $=40$ & $\mathbf{5 0}$ & $\mathbf{5 0}$ & $\mathbf{1 0}$ \\
\hline
\end{tabular}

If, for example, participant A transfers two points to participant B, participant A will receive 88 points, participant $\mathrm{B} 12$ points, and participant $\mathrm{C} 10$ points.

\section{The competitive mechanism}

In the competitive mechanism, participants $\mathrm{B}$ and $\mathrm{C}$ compete with one another. The competition involves accepting a certain distribution of the 110 points. The starting point is determined by the following distribution:

\begin{tabular}{|c|c|c|}
\hline $\begin{array}{c}\text { Points for } \\
\text { participant A }\end{array}$ & $\begin{array}{c}\text { Points for } \\
\text { participant B }\end{array}$ & $\begin{array}{c}\text { Points for } \\
\text { participant C }\end{array}$ \\
\hline $\mathbf{9 0}$ & $\mathbf{1 0}$ & $\mathbf{1 0}$ \\
\hline
\end{tabular}


The number of points that participant $\mathrm{B}$ or participant $\mathrm{C}$ can earn during the competition phase begins at 10 points and increases by one point every second.

The first participant (B or $\mathrm{C}$ ) to accept the distribution receives the corresponding number of points. The other participant receives 10 points.

If participant A chooses the competitive mechanism, his or her number of points depends on which distribution participant B or C accepts. Participant A's number of points begins at 90 and decreases by one point every second.

The following table gives a survey of the distributions that can result from the competitive mechanism:

\begin{tabular}{|c|c|c|c|}
\cline { 2 - 4 } \multicolumn{1}{c|}{} & $\begin{array}{c}\text { Points for } \\
\text { participant A }\end{array}$ & $\begin{array}{c}\text { Points for the } \\
\text { first participant } \\
\text { (B or C) to } \\
\text { accept the } \\
\text { distribution }\end{array}$ & $\begin{array}{c}\text { Points for the } \\
\text { other participant } \\
\text { (B or C) }\end{array}$ \\
\hline At the beginning & $\mathbf{9 0}$ & $\mathbf{1 0}$ & $\mathbf{1 0}$ \\
\hline after 1 second & $\mathbf{8 9}$ & $\mathbf{1 1}$ & $\mathbf{1 0}$ \\
\hline after 2 seconds & $\mathbf{8 8}$ & $\mathbf{1 2}$ & $\mathbf{1 0}$ \\
\hline after 3 seconds & $\mathbf{8 7}$ & $\mathbf{1 3}$ & $\ldots$ \\
\hline$\ldots$ & $\ldots$ & $\mathbf{1 0}$ & $\mathbf{1 0}$ \\
\hline
\end{tabular}

The resulting distribution thus depends on how much time elapses until either participant B or participant $\mathrm{C}$ accepts the distribution.

If, for example, participant $\mathrm{C}$ accepts after 2 seconds, then participant $\mathrm{A}$ receives 88 points, participant $\mathrm{C} 12$ points, and participant $\mathrm{B} 10$ points.

After 40 seconds, the distribution is at 50-50-10, and will no longer change. The participant B or $\mathrm{C}$ who first accepts then receives 50 points; the other participant receives 10 points. 


\section{Point deductions by participants $\mathrm{B}$ or $\mathrm{C}$}

Once the distribution of the points has been determined - either by means of the direct decision or the competitive mechanism - the computer will randomly select either participant B or C. This random selection is independent of the previous course of events. If, for example, the competitive mechanism was chosen, the random selection is independent of who first accepted the distribution. Participants B and C always have a 50\% probability of being selected by the computer.

The participant $\mathrm{B}$ or $\mathrm{C}$ whom the computer randomly chooses receives five additional points. The selected participant can use the additional points to deduct points from the other participants. He or she relinquishes 0.1 additional points for every point he deducts from the other participants. The randomly selected participant $\mathrm{B}$ or $\mathrm{C}$ thus has the possibility of using the five additional points to deduct up to 50 points from the other participants. He or she can also deduct less than 50 points from the other participants, thus retaining a part, or all, of the additional points.

The point deductions can be divided among the other participants in any way. However, a participant cannot lose more points than he or she earned in the direct decision or the competitive mechanisms. 


\section{Examples}

In order to illustrate how the final payments are determined, please look at the following examples, which were chosen entirely randomly:

Example 1: Participant A selects the direct decision mechanism. He or she transfers 35 points to participant B. After the transfer decision, A thus has $90-35=55$ points, participant $\mathrm{B}$ has $10+35=45$ points, and participant $\mathrm{C}$ has 10 points. The computer randomly selects participant B to deduct points, granting him or her 5 additional points. Participant B decides to deduct 31 points from participant $\mathrm{A}$ and 9 points from participant $\mathrm{C}$. He or she thus deducts a total of 40 points, thus giving up $40 \times 0.1=4$ of the additional points. The following payments thus result:

\begin{tabular}{|c|c|c|}
\hline $\begin{array}{c}\text { Points for } \\
\text { participant A }\end{array}$ & $\begin{array}{c}\text { Points for } \\
\text { participant B }\end{array}$ & $\begin{array}{c}\text { Points for } \\
\text { participant C }\end{array}$ \\
\hline $55-31=24$ & $45+5-4=46$ & $10-9=1$ \\
\hline
\end{tabular}

Example 2: Participant A selects the competitive mechanism for making the distribution. Participant B accepts the division after 6 seconds. After the competitive mechanism, participant $A$ thus has 84 points, participant $B$ has 16 points, and participant $C$ has 10 points. The computer randomly selects participant $\mathrm{C}$ to deduct points, granting him or her 5 additional points. He or she decides to deduct 10 points from participant $\mathrm{A}$ and 5 points from participant B. He or she thus deducts 15 points and therefore gives up $15 \times 0.1=1.5$ of the additional points. The following payments thus result:

\begin{tabular}{|c|c|c|}
\hline $\begin{array}{c}\text { Points for } \\
\text { participant A }\end{array}$ & $\begin{array}{c}\text { Points for } \\
\text { participant B }\end{array}$ & $\begin{array}{c}\text { Points for } \\
\text { participant C }\end{array}$ \\
\hline $84-10=74$ & $16-5=11$ & $10+5-1,5=13,5$ \\
\hline
\end{tabular}

Example 3: The participant randomly chosen for deducting points (B or C) does not deduct any points from the other participants. In this case, all participants receive the points determined in the direct decision or the competitive mechanism, and furthermore, the participant $\mathrm{B}$ or $\mathrm{C}$ chosen for deducting points receives the additional five points. 


\section{Procedure on the computer}

Participant A makes his or decision about the procedure to be used for determining the distribution of points on the screen below:

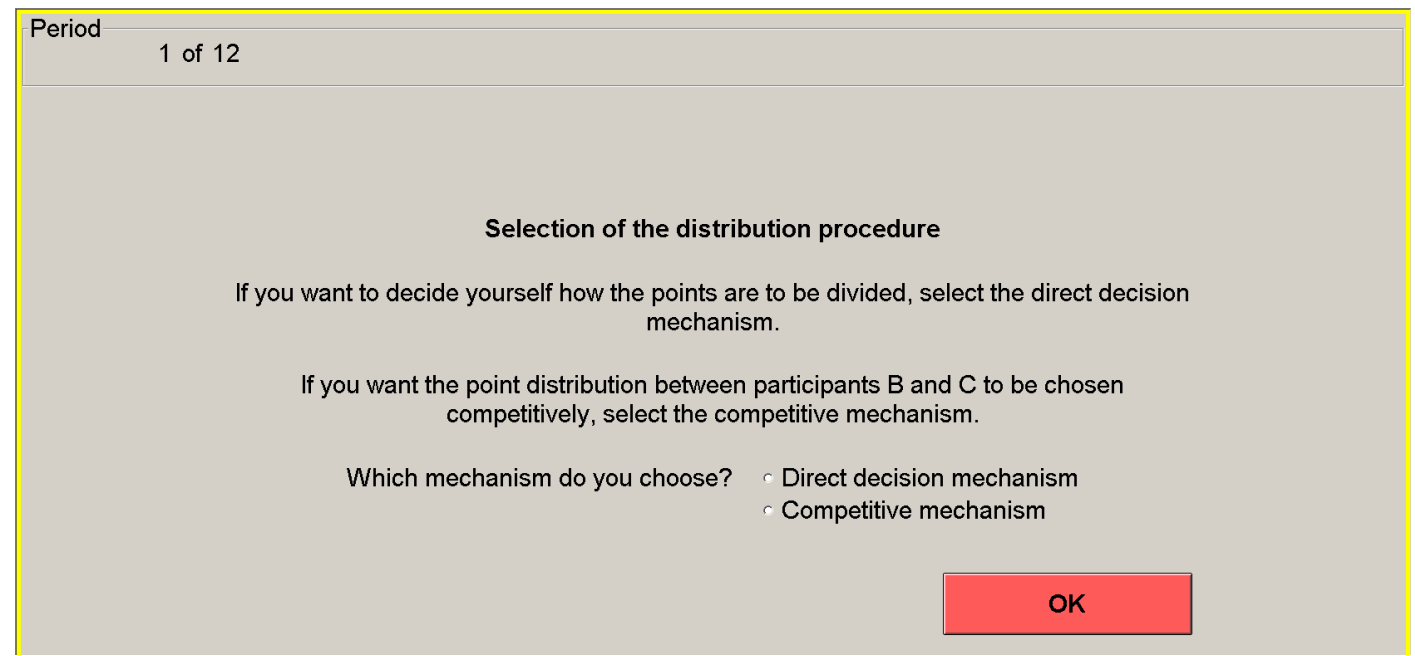

On each screen, you can see the present period in the upper line. In this example, it is the first of twelve periods ( 1 of 12).

Participant A chooses the procedure that he or she would like to use and then clicks on "OK". 
If participant $\mathrm{A}$ decided to distribute the costs him/herself using the direct decision mechanism, he or she determines the exact distribution of costs on the screen below:

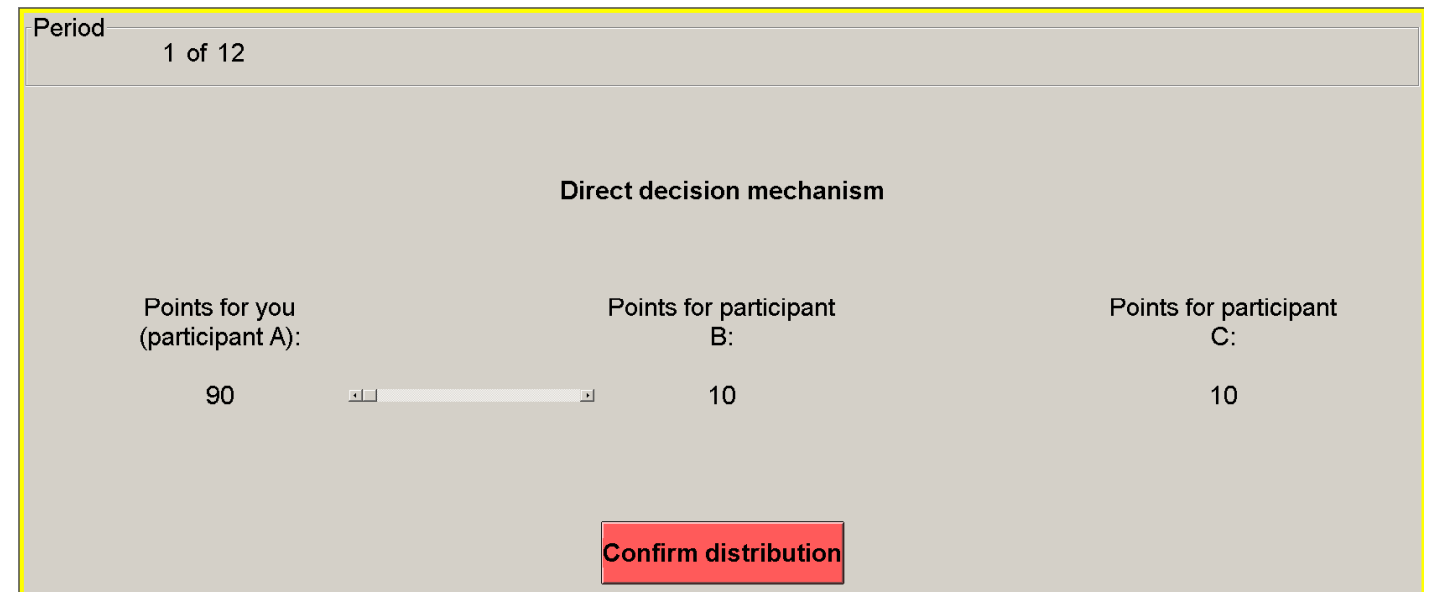

Participant A can move the scroll bar between the left and the middle columns and thus determine the distribution of points between him/herself and participant B. If the scroll bar is all the way to the left (as in the example above), participant A transfers no points to participant B. If the scroll bar is all the way to the right, participant A transfers 40 points to participant $\mathrm{B}$. If the scroll bar is in a position in between, the corresponding number of points is transferred to participant $\mathrm{B}$. The exact number of points that any position yields is indicated directly on the screen. After reaching the desired point distribution, participant A clicks on "Confirm distribution" to confirm his or her decision. 
If participant $\mathrm{A}$ decided to determine the distribution through the competitive mechanism, participant $\mathrm{B}$ and $\mathrm{C}$ are informed accordingly and the competition phase begins. Participants $\mathrm{B}$ and $\mathrm{C}$ make their decisions on the following screen:

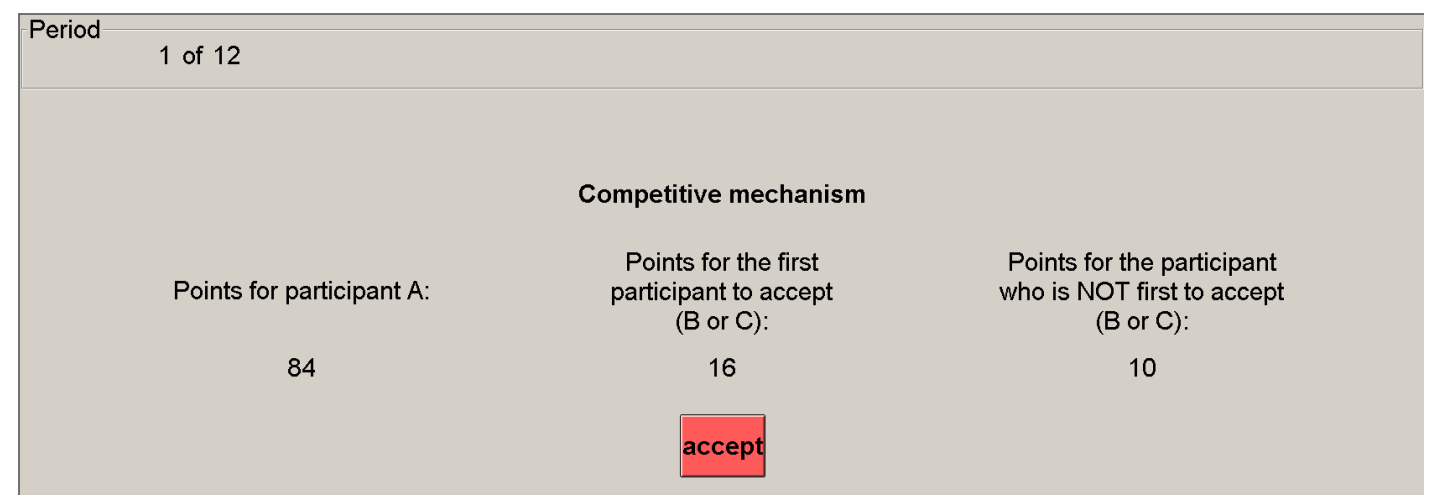

The screen shows the distributions that result in each second. The points for participant A are on the left side; the middle shows the points for the participant (B or C) who is first to accept the distribution (by clicking on the "accept" button), and the right shows the number of points for the participant (B or $\mathrm{C}$ ) who is not the first to accept. This participant always receives 10 points.

The points for participant A and for the participant who accepts first (B or C) change from second to second. In the example shown above, you see the distribution that results after 6 seconds.

In the next second, participant A's number of points will reduce to 83 and the number of points for the participant who is first to accept will increase to 17.

In the second after that, participant A's number of points will reduce to 82 and the number of points for the participant who is first to accept will increase to 18 , etc.

The competition phase concludes as soon as either participant B or participant $\mathrm{C}$ clicks on the "accept" button. 
In a next step, all participants are informed of the resulting distribution. If participant A chose the direct decision mechanism, participant $\mathrm{B}$ and $\mathrm{C}$ will be informed of the distribution that participant A chose; if participant A chose the competitive mechanism, participant A will be informed of the result of the competition.

Participant $\mathrm{B}$ or $\mathrm{C}$ will then be chosen randomly. The randomly chosen participant will receive five additional points which he or she can use entirely or partially to deduct points from the other participants.

Before participants $B$ and $C$ learn who has the possibility of deducting points, both enter how many points they would like to deduct from the other two participants in case the computer randomly chooses them.

If random chance determines that participant B may deduct the points, participant B will receive five additional points and his or her decision will be implemented. If random chance determines that participant $\mathrm{C}$ may deduct the points, participant $\mathrm{C}$ will receive five additional points and his or her decision will be implemented. As neither participant $\mathrm{B}$ nor participant $\mathrm{C}$ knows if the computer will select him or her randomly, each should make the decision carefully. The probability that the decision will be implemented amounts to $50 \%$.

In this example, you see participant C's screen; that of participant B is analogous.

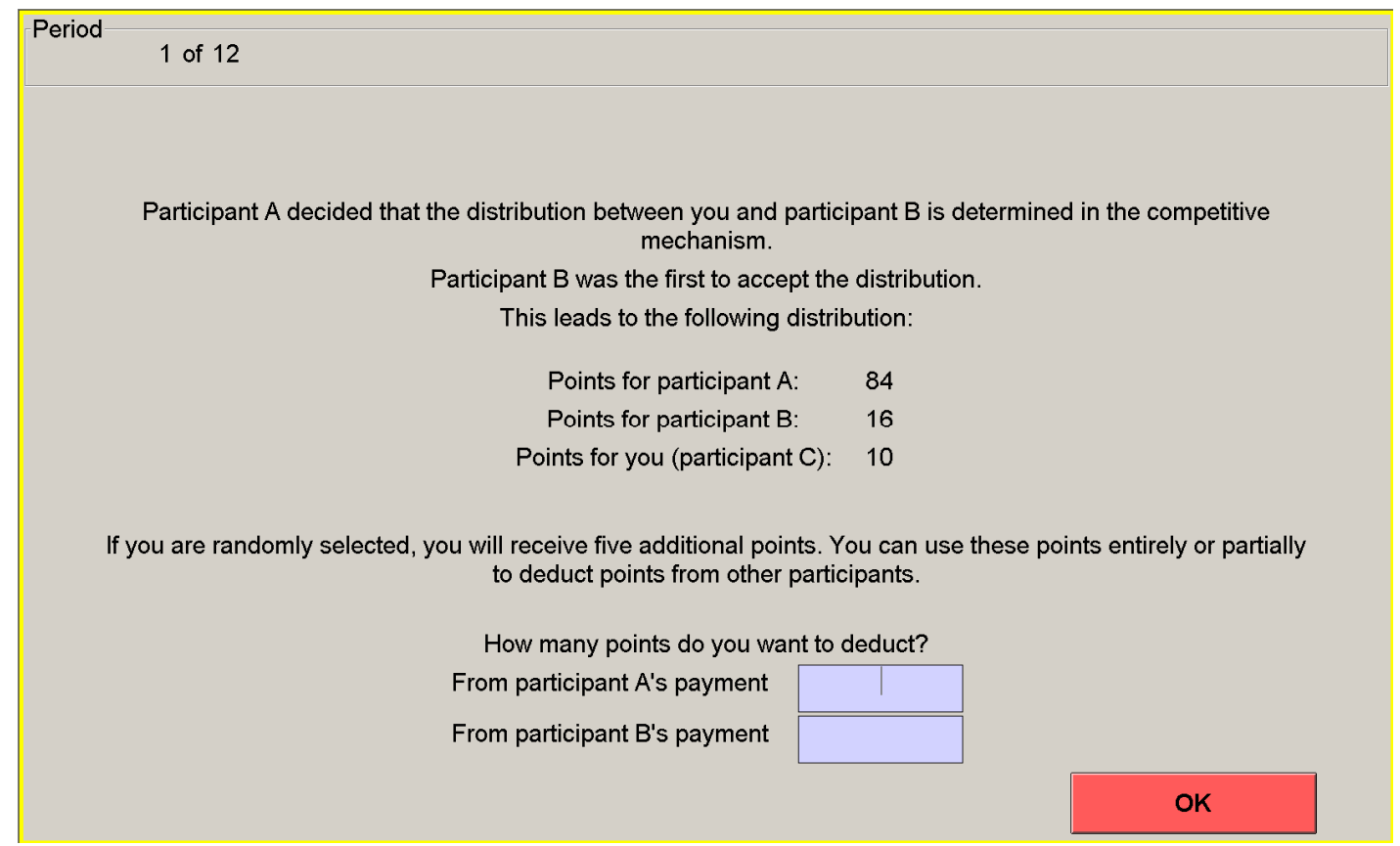


In this example, participant $B$ accepted the point amount of 16 points, which results in the competition phase after 6 seconds.

Participant $\mathrm{C}$ enters the number of points that he or she would like to deduct from the other participants in the corresponding fields. For each point that participant $\mathrm{C}$ deducts from another participant, he or she loses 0.1 additional point. If participant $\mathrm{C}$ does not want to deduct any points, he or she enters " 0 " in both fields. In this case, he or she retains all five additional points.

The decisions can be changed until the OK button is clicked on.

After participants $\mathrm{B}$ and $\mathrm{C}$ have decided on the point deductions, the computer will randomly choose one of these participants, and the chosen participant's point deductions will be implemented.

The other participant's point deductions will neither be implemented nor will this participant receive any additional points. 
At the end of a period, all participants will be informed about the payments that resulted. In the example here you see participant B's screen. The screens of participants A and C are analogous.

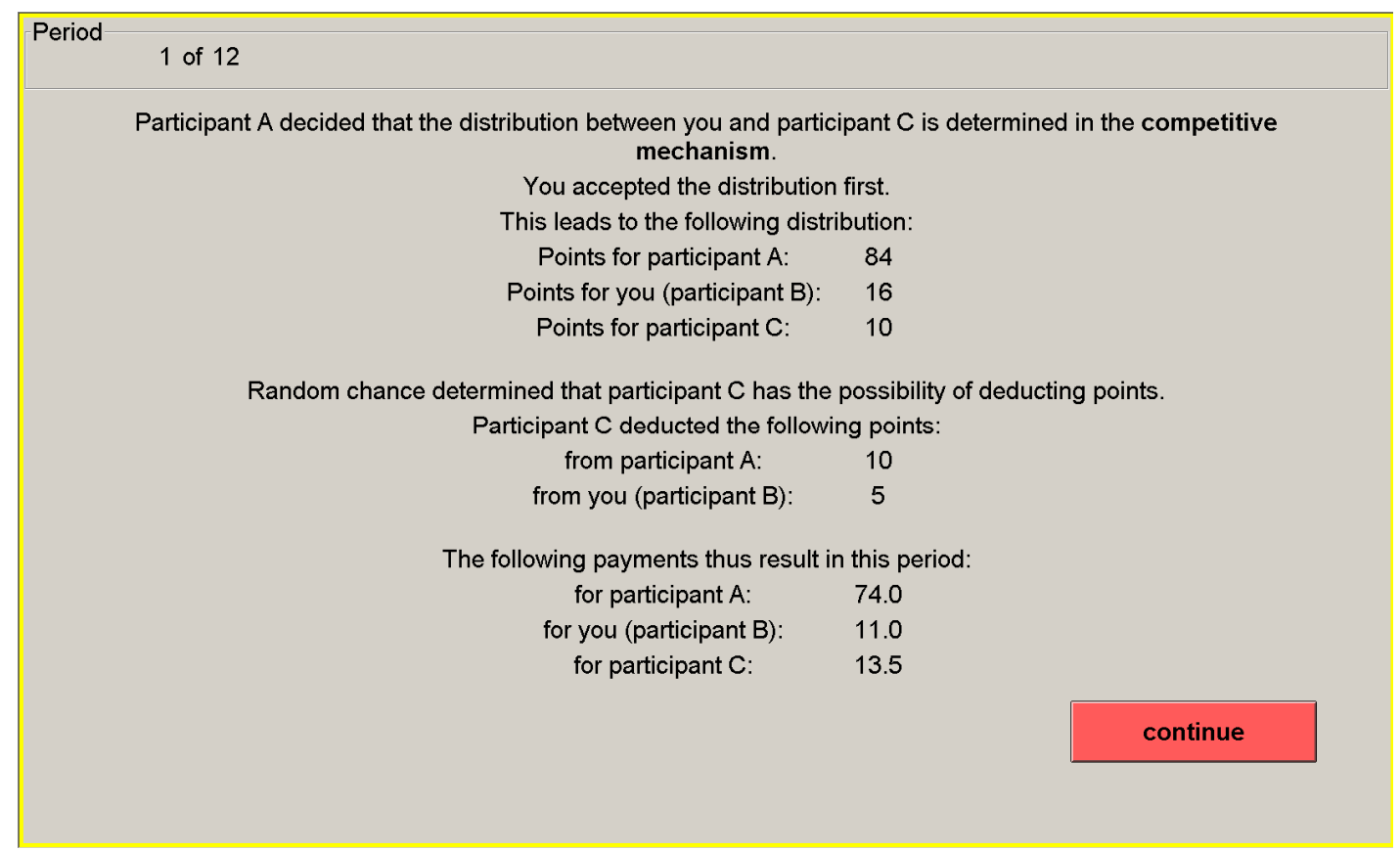

Once all participants have pressed the "continue" button, the next period begins, during which a new participant $A$, a new participant $B$ and a new participant $C$ are randomly matched together.

At the end of the study, one of the 12 periods will be randomly selected. The payments from this randomly chosen period will determine your income in this study. The points you earned in this period will be converted to Euros and paid out to you, together with the initial endowment in cash. As you do not know which period will be randomly selected, you should consider your decisions in every period very carefully.

Do you have any questions? If yes, please raise your hand. We will come to you at your carrel.

If you do not have questions, please complete the control questions on the next page. 


\section{Control questions}

Please answer the following control questions. They only serve the purpose of making you familiar with the study. The decisions and numerical amounts in the control questions are chosen completely randomly; they should not be considered an indication of or a suggestion how you could decide. Your answers to the control questions have no effect on your payment at the end of the study.

Please enter your answers directly into the computer. You can check this way whether your answers are correct. If you have a question, please raise your hand. The study cannot begin until all participants have answered the questions correctly.

1. Participant $\mathrm{A}$ decides for the direct decision mechanism and transfers 5 points to participant B. After the transfer decision, participant A thus has 85 points, participant $\mathrm{B}$ 15 points, and participant $C 10$ points. Partcipant $C$ is randomly chosen to deduct points; he or she can deduct points from other participants and thus receives five additional points. Participant $\mathrm{C}$ then decides to make the following deductions, which appear in bold print below.

\begin{tabular}{|c|c|c|c|}
\hline & Participant A & Participant B & Participant C \\
\hline Distribution & 85 & 15 & 10 \\
\hline $\begin{array}{c}\text { - Deducted } \\
\text { points }\end{array}$ & $\mathbf{1 5}$ & $\mathbf{5}$ & - \\
\hline $\begin{array}{c}\text { remaining } \\
\text { additional points }\end{array}$ & - & - & - \\
\hline$=$ Payment? & - & - & - \\
\hline
\end{tabular}

Please determine the payment (in points) that results for each participant.

2. What is the maximum number of points that participant $\mathrm{C}$ could deduct from participant A in the example above?

3. What is the maximum number of points that participant $\mathrm{C}$ could deduct from participant $\mathrm{B}$ in the example above? 
4. Participant A decides for the direct decision mechanism and transfers 36 points to participant B. After the transfer decision, participant A thus has 54 points, participant B 46 points, and participant $C 10$ points. Partcipant $B$ is randomly chosen to deduct points; he or she can deduct points from other participants and thus receives five additional points. Participant B then decides to make the following deductions, which appear in bold print below.

\begin{tabular}{|c|c|c|c|}
\hline & Participant A & Participant B & Participant C \\
\hline Distribution & 54 & 46 & 10 \\
\hline $\begin{array}{l}\text { - Deducted } \\
\text { points }\end{array}$ & $\mathbf{4 0}$ & - & $\mathbf{6}$ \\
\hline $\begin{array}{l}\text { + remaining } \\
\text { additional points }\end{array}$ & - & - & - \\
\hline$=$ Payment? & - & - & - \\
\hline
\end{tabular}

Please determine the payment (in points) that results for each participant.

5. Participant A decides to determine the distribution in the competitive mechanism. Participant $\mathrm{C}$ first decides to accept a distribution; this is after 25 seconds. Partcipant $\mathrm{C}$ is randomly chosen to deduct points; he or she can deduct points from other participants and thus receives five additional points. Participant $\mathrm{C}$ then decides to make the following deductions, which appear in bold print below.

\begin{tabular}{|c|c|c|c|}
\hline & Participant A & Participant B & Participant C \\
\hline \multicolumn{1}{|c|}{ Distribution } & & & - \\
\hline $\begin{array}{l}- \text { Deducted } \\
\text { points }\end{array}$ & $\mathbf{2 7}$ & $\mathbf{3}$ & - \\
\hline $\begin{array}{l}\text { remaining } \\
\text { additional points }\end{array}$ & - & - & - \\
\hline$=$ Payment? & - & & - \\
\hline
\end{tabular}

Please determine the distribution that participant $\mathrm{C}$ has in the competitive mechanism after 25 seconds and the payment (in points) that results for each participant. 
6. Before the computer determines which participant has the possibility to deduct points, participant $\mathrm{B}$ decides to deduct a total of 23 points from the other two participants, in case he or she is randomly chosen. The computer decides randomly that participant $\mathrm{C}$ has the possibility of deducting points. How many additional points does participant $\mathrm{B}$ - who is not randomly chosen - receive?

Will the 23 points that participant B - the participant who was not chosen - wanted to deduct from participants $\mathrm{A}$ and $\mathrm{C}$ be deducted?

YES / NO (Please select the appropriate answer)

7. Participant A decides to determine the distribution in the competitive mechanism. Participant B first decides to accept a distribution; this is after 2 seconds. Partcipant $\mathrm{C}$ is randomly chosen to deduct points; he or she can deduct points from other participants and thus receives five additional points. Participant $\mathrm{C}$ then decides to make the following deductions, which appear in bold print below.

\begin{tabular}{|l|c|c|c|}
\hline & Participant A & Participant B & Participant C \\
\hline \multicolumn{1}{|c|}{ Distribution } & & & \\
\hline $\begin{array}{l}\text { - } \begin{array}{l}\text { Deducted } \\
\text { points }\end{array} \\
+\begin{array}{l}\text { remaining } \\
\text { additional points }\end{array}\end{array}$ & - & $\mathbf{0}$ & - \\
\hline$=$ Payment? & - & - & - \\
\hline
\end{tabular}

Please determine the distribution that participant $\mathrm{B}$ has in the competitive mechanism after 2 seconds and the payment (in points) that results for each participant.

If you have a question, please raise your hand. The study will begin as soon as all participants have correctly solved the control questions and entered the answers into the computer. 